\title{
The Impact of Renewable Energy Consumption on the Human Development Index in Selected Countries: Panel Analysis (1990-2015)
}

\author{
Haidy Amer \\ School of Business, Arab Academy for Science, Technology and Maritime Transport, Alexandria, Egypt
}

Email address:

r02hma14@abdn.ac.uk

To cite this article:

Haidy Amer. The Impact of Renewable Energy Consumption on the Human Development Index in Selected Countries: Panel Analysis (1990-2015). International Journal of Economy, Energy and Environment. Vol. 5, No. 4, 2020, pp. 47-68. doi: 10.11648/j.ijeee.20200504.12

Received: August 14, 2020; Accepted: August 31, 2020; Published: September 10, 2020

\begin{abstract}
Human Development Index combines three well known dimensions: long healthy life, education and standard of living. Energy influences all these dimensions either directly or indirectly, that is one of the reasons why countries should focus on reducing greenhouse gas emissions that come directly from energy use, and improve energy efficiency activities while at the same time not affecting the human development process. By studying the relationship between energy and human development, through PVAR analysis, this paper contributes to the efforts of promoting renewable energy and energy efficiency while acting globally for climate change mitigation. The analysis covers 4 panels representing four income levels distributed among the globe throughout the period from 1990 to 2015. First and second panel unit root and cointegration tests are being applied after examining for cross sectional correlation between each panel units, then PVAR analysis is being conducted for each panel through a system GMM methodology. Results show that in all of the four panels the impact of renewable energy consumption in reducing the per capita $\mathrm{CO} 2$ emissions is found to be insignificant for all of the four panels. Moreover, the impact of the renewable energy consumption on the HDI is found to be insignificant among the selected countries in all of the panels except the lower middle-income countries.
\end{abstract}

Keywords: Renewable Energy Consumption, Energy Intensity, Human Development Index

\section{Introduction}

Climate change and global warming have attracted considerable worldwide attention. Many studies have focused on the relationships between economic growth and $\mathrm{CO}_{2}$ emissions as well as economic growth and energy over the last two decades. It has been observed that higher economic growth causes environmental degradation and threatens the sustainability of the environment where economic growth is closely linked to energy consumption. Higher economic growth requires a higher level of energy consumption and thus is suspected to be responsible for higher levels of $\mathrm{CO}_{2}$ emissions. This notion attracted the world's attention in the 1990's because of the potential threats to the ecosystem, that is why more attention is given to renewable energy resources which appear to be one of the most efficient and effective solutions to overcome the several energy related environmental problems. According to Dincer (2000) [9], as there is a close connection between renewable energy and sustainable development, the improvement of renewable energy technologies will assist sustainable development. Within the timeline of the sustainable development goals, renewable energy can offer solutions for the dual objective of ensuring economic growth and the imperative to decarbonize economies across the globe. The business case for renewable energy is further strengthened by the socioeconomic benefits it can offer. Renewable energy benefits therefore play a critical role in informing policy decisions and tipping the balance in favor of low-carbon investments. All of these effects of employing renewable energy can result in a greater benefit not only on the economic growth but also on the development level of any country, leading eventually to a higher human development index and better standards of living.

The innovative contribution of this analysis is to determine the short run and /or long-run relationship between renewable energy consumption and the HDI, as a measure of human well-being. This paper addresses some important issues. First, 
the relationship between consumption of renewable energy and HDI of the four panels and which panel benefits the most from consuming renewable energy with regard to its development level. Second, the relationship between renewable energy consumption and energy intensity for each panel in addition to how these variables are related to the different panels with their different stage of development. Third, the relationship between renewable energy consumption, per capita $\mathrm{CO}_{2}$ emissions and $\mathrm{HDI}$, and which panel is benefited more with respect to the environmental degradation. Fourth, comparing the effects of openness to trade activities and financial development on the different levels of human development of the four-panels and at which stage of development do their role increase and/or decrease while at the same time comparing their influence to the renewable energy consumption. In conclusion, this paper analysis is new in examining this kind of relationships among the whole globe. It tries to assign a different approach by tackling the shortcomings in the literature throughout a more comprehensive indicator for the standards of living, rather that the gross domestic product per capita, based on the Human Development Index. In addition to, a system of simultaneous equations that outline the important feedback relationships between HDI, renewable energy consumption, trade openness, financial development, energy intensity and environmental pollution is being employed through a global panel that represent the four income levels all around the world.

\section{Literature Review}

\subsection{Literature Survey on Energy Consumption and HDI Index}

By drawing on the relationship between energy consumption in its aggregate form and the human development, it can be found that Martinez, D. M. and Ebenhack, B. W., (2008) [24], studied the relationship between the HDI and per capita energy consumption for 120 nations. Their findings confirmed the presence of a strong relationship between the HDI values and energy consumption for the majority of the world countries. Three important trends have been identified as emerged from the data;(a) a sharp rise in human development relative to energy consumption for energy-poor nations,(b) a moderate rise for transitioning nations and (c) no rise in human development with respect to the developed nations exhausting large amounts of modern energy. Therefore, more improvements and development in energy consumption can potentially cause large gains in human development specifically for the world's poorest nations. These results are in line with Mazur, A., (2011) [25], who attempted to study the correlation between the electricity consumption, energy consumption and HDI. He tested correlations between these variables rather than the causality relationships through graphs using longitudinal data from (1980-2006) for 21 industrialized countries. Results have shown that electricity consumption was crucial for people to improve their well-being in less-developed countries while, in industrialized nations, increasing electricity consumption has little relationship with improving quality of life.

Likewise, Nui et al. (2013) [27], they analyzed the causality between electricity consumption and human development for a group of 50 countries selected from all over the world and divided into four groups according to income level throughout the period of (1990-2009). The researchers have selected five indexes to reflect the human development level of the studied countries, which are; per-capita GDP, per-capita consumption expenditure, urbanization rate, life expectancy at birth and the adult literacy rate. Findings reveal the existence of long-run bidirectional causality between electricity consumption and the five indicators. Moreover, the higher the income of a country, the greater is its electricity consumption and the higher is its level of human development. Specifically, as income increases, the contribution of electricity consumption to GDP and consumption expenditure increases, but the urbanization rate, life expectancy at birth and adult literacy rate present a weakening trend. This is mainly due to the latter indicators in high-income countries are increasing to converge. These results are also in line with that of Martinez, D. M. et al. (2008) and Mazur, A., (2011) [24, 25], by confirming that energy consuming in the high income countries do not add to their development levels.

\subsection{Literature Survey on Renewable Energy Consumption and HDI Index}

In an analysis for the role of renewable energy consumption with respect to the human development, Pîrlogea, C., (2012) [32] examined the relationship between the human development index (HDI) as a dependent variable and renewable energy consumption, fossil fuel energy consumption, $\mathrm{CO}_{2}$ emissions intensity and energy intensity as independent variables for the period of (1997-2008). The countries selected were for six European states, with high (Bulgaria, Romania) and very high (Portugal, Poland, Ireland and Netherlands) HDI values in 2010. Results showed that fossil fuel consumption has a negative relationship with HDI for Romania and Bulgaria and positive for countries with very high HDI. Regarding renewable consumption, with no exception, it positively influences human development referring to the important role that renewable energy plays for these countries. In addition to, the energy intensity variables contributed negatively to the HDI, where lower leveled of energy intensity entails better human development.

Kazar, G. and Kazar, A., (2014) [20], in their study utilized the human development index for development level and the relationship between renewable electricity net generation values and development has been examined within a panel framework that includes 154 countries. The countries were divided into 5 panels; all countries, very high human development countries, high human development countries, middle human development and low human development countries. The Study covered two different periods; (1980-2010) to examine long-term effects and (2005-2010) yearly data for short-term effects. For both short run and long run, findings exhibited a uni directional Granger causality 
from development to renewable energy generation for the high human development countries while a bidirectional causality exists for the middle-income countries. Whereas for the very high human development countries and low human development countries there is no causality between renewable energy and development. Accordingly, the findings disclosed that low human developed countries have to break the vicious cycle of underdevelopment in ordered to can reach higher development levels.

Soukiazis, E., et al. (2017) [37] analyzed the impact of renewable energy consumption on the Human Development Index (HDI) in addition to other variables that have been utilized in the analysis like $\mathrm{CO}_{2}$ emissions, $\mathrm{R} \& \mathrm{D}$ and human and physical capital. The analysis has been conducted through developing a simultaneous equation system approach for a panel of 28 OECD countries over the period of (2004-2015). By focusing more on the impact of renewable energy on the HDI, results showed that renewable energy consumption along with human and physical capital are considered important factors in explaining the sustainable development level of the countries considered. Outcomes highlighted that the renewable energy share positively affected the level of development with a high statistical significance.

In a recent study, Wang, Z. et al. (2018) [41] explored the relationship between renewable energy consumption, economic growth and human development index in Pakistan throughout the period of (1990-2014). Empirical results, according the VECM Granger causality tests, suggested the presence of long run and short run unidirectional Granger causal relationship going from renewable energy and $\mathrm{HDI}$ to $\mathrm{CO}_{2}$ emissions. Regarding the short-run causality, and with regard to the HDI, results supported that renewable energy consumption did not improve the situation of the human development process in Pakistan and that in the long-run conversely low human development leads to environmental pollution.

In conclusion, the evidence presented in these previous studies suggests that the renewable energy has in fact an important role in the economic development specifically for the middle-income countries that are trying to catch on the path of the high income countries and follow it. However, such an impact can be observed more clearly in the long-run rather the short run.

\section{Materials and Methods}

\subsection{Data}

To conduct this chapter empirical analysis, secondary data has been obtained from two sources which are the World Development Indicators (WDI 2019) and the United Nations Development Programme (UNDP 2018). Six variables are going to be used which are the carbon dioxide emissions per capita $\left(\mathrm{PCO}_{2}\right)$, human development index $(\mathrm{HDI})$, renewable energy consumption (REC), energy intensity (MJ/\$2011 PPP GDP, EI), financial development (FD) and trade openness (TO). Carbon dioxide emissions are those stemming from the burning of fossil fuels and the manufacture of cement. The Human Development Index (HDI) is a summary measure of average achievement in key dimensions of human development: a long and healthy life, being knowledgeable and have a decent standard of living. Renewable energy consumption is the share of renewable energy in total final energy consumption. Energy intensity level of primary energy is the ratio between energy supply and gross domestic product measured at purchasing power parity. Energy intensity is an indication of how much energy is used to produce one unit of economic output. Trade is the sum of exports and imports of goods and services measured as a share of gross domestic product. Financial development is the domestic credit to private sector refers to financial resources provided to the private sector by financial corporations, such as through loans, purchases of non-equity securities, and trade credits and other accounts receivable that establish a claim for repayment.

Table 1. List of Countries.

\begin{tabular}{ll}
\hline Panel & List of countries \\
\hline Low income & Benin, Burundi, Central African Republic, Congo Rep., Gambia, Guinea, Haiti, Malawi, Mozambique, Nepal, Rwanda, Sierra Leone, \\
countries & Tanzania, Togo, Uganda. \\
Lower middle & Bangladesh, Bolivia, Cote d'Ivoire, Arab Republic of Egypt, El Salvador, Ghana, Honduras, India, Indonesia, Kenya, Lao PDR, \\
income countries & Mauritania, Mongolia, Morocco, Nicaragua, Papua New Guinea, Philippines, Senegal, Sudan, Tunisia, Ukraine, Vietnam, Zimbabwe. \\
Upper middle & Albania, Algeria, Argentina, Armenia, Belize, Botswana, Brazil, Bulgaria, China, Colombia, Costa Rica, Dominica, Dominican \\
income countries & Republic, Ecuador, Guatemala, Gabon, Guyana, Iran, Jordon, Malaysia, Mauritius Mexico, Namibia, Paraguay, Peru, South Africa, \\
& Srilanka, Thailand, Turkey, Tonga, Venezuela, RB. \\
High income & Australia, Austria, Belgium, Chile, Cyprus, Denmark, Finland, France, Germany, Greece, Hong Kong, Hungary, Ireland, Israel, Italy, \\
countries & Japan, Luxemburg, Malta, New Zeland, Norway, Poland, Panama, Portugal, Saudi Arabia, Singapore, Spain, Sweden, Switzerland, \\
\hline
\end{tabular}

Notes: The source from World Bank database.

All the variables in the specified model are transformed to double log form where such transformation is helpful to obtain the relative normal distribution of the data. The estimated coefficients in this form are the elasticities of the explanatory variables to the dependent variable, so the results will be meaningful and easy to interpret. A complete dynamic panel VAR models will be estimated by including all of the variables with their optimal lags. Four panels of 101 countries are being considered reflecting the four levels of income; as 32 high, 31 upper-middle, 23 lower-middle and 15 low-income level countries. These are scattered across different continents (except Antarctica). The selected countries are divided into four groups according to the latest World Bank income-grouping standards (2019). The countries selected and the four panels are shown in table 1 . 


\subsection{Methodology}

\subsubsection{Testing for Cross Section Dependence}

It is becoming now important to check for the presence of cross section dependence among the panel units. The presence of cross sectional correlation of errors in the panel is likely to be common now and thus disregarding it can have some serious outcomes like affecting the unbiasedness and consistency of the standard panel estimates leading to wrong inferences. Economically speaking, the cross-section dependence problem can be explained in a way so that if some of the units shaping the panel are affected by a shock, then the other units of panel will be influenced as well. Different tests are being used to investigate the cross-sectional dependency in panel data, among them are Breusch and Pagan (1980) [5] and Pesaran (2003) [31].

Consider the following panel data model

$$
y_{i t}=\alpha_{i}+\beta_{i} X_{i t}+u_{i t} i=1,2, \ldots, N, t=1,2, \ldots, T
$$

Where $i$ indexes the cross-section dimension and $t$ the time series dimension, $X_{i t}$ is a $\mathrm{k} \times 1$ vector regressors. The coefficients $\beta_{i}$ are allowed to vary across $i$ and $\alpha_{i}$ represents time-invariant individual parameters. For each $i$, $u_{i t} \sim \operatorname{IID}\left(0, \sigma_{\mu i}^{2}\right)$, for all $t$, although they could be cross-sectionally correlated yet, the assumption of no serial correlation remains. Moreover, Pesaran calls attention to that while this specification has cross-section specific coefficients, the depicted beneath are likewise can be also applicable to the more restrictive fixed and random effects models.

The general null hypothesis of zero cross-equation error correlations: can be expressed in terms of the correlations between the disturbances in different cross-section units:

$$
\begin{gathered}
H_{0}: \hat{\rho}_{i j=} \hat{\rho}_{j i=} \operatorname{Corr}\left(u_{i t}, u_{j t}\right)=0 \text { For } i \neq j \\
H_{0}: \hat{\rho}_{i j=} \hat{\rho}_{j i=} \operatorname{Corr}\left(u_{i t}, u_{j t}\right) \neq 0 \text { For some } i \neq j
\end{gathered}
$$

For balanced panels, $\hat{\rho}_{i j}$ is the sample product-moment correlation coefficients of the residuals as follows,

$$
\hat{\rho}_{i j}=\hat{\rho}_{j i}=\frac{\sum_{t=1}^{T} u_{i t} u_{j t}}{\left(\sum_{t=1}^{T} u_{i t^{2}}\right)^{1 / 2}\left(\sum_{t=1}^{T} u_{j t^{2}}\right)^{1 / 2}}
$$

In addition, $u_{i t}$ is the Ordinary Least Squares (OLS) estimate of $u_{i t}$ defined by,

$$
u_{i t}=y_{i t}-\hat{\beta}_{i} X_{i t}
$$

Where $\hat{\beta}_{i}$ being the estimates of $\beta_{i}$ computed using the OLS regression of $y_{i t}$ on $X_{i t}$ for each $i$ separately.

LM test, which is evolved, by Bresuch and Pagan (1980) [5] is based on the Lagrange Multiplier (LM) statistic and is shown as below;

$$
L M=T \sum_{i=1}^{N-1} \sum_{j=i+1}^{N} \hat{\rho}_{i j}^{2}
$$

It should be noticed that under the null, the test statistic $L M$ is based on the residuals from individual-specific OLS regressions as in (1) and is used when $N$ is constant and
$T \rightarrow \infty$. However, the estimates get biased more as $N$ gets large and hence to deal with the large $N$ bias of the LM test, Pesaran (2003) [31] has proposed the following alternative;

$\mathrm{CD}$ test as previously mentioned is also another test to examine cross-sectional dependency and is calculated as the following;

$$
C D=\sqrt{\frac{2 T}{N(N-1)}}\left[\sum_{i=1}^{N-1} \sum_{j=i+1}^{N} \hat{\rho}_{i j}\right] \stackrel{d}{\rightarrow} N(0,1)
$$

This test depends on the sum of correlation coefficient squares among cross section residuals and is asymptotically standard normal distributed that is utilized in cases where $N \rightarrow \infty$ and $T$ is sufficiently large. It has the same null and alternative hypothesis of this test as with the LM test. However, unlike the LM statistic, the CD statistic has mean at exactly zero for fixed values of $T$ and $N$, under a wide range of panel-data models, including homogeneous/heterogeneous dynamic models and non-stationary models.

Accordingly, both of the high and upper middle income countries will depend more on the Pesaran (CD) test since they have the number of panel units greater than the time series while the lower middle and lower income countries will depend more on Bresuch and Pagan (LM) test since they have the opposite.

\subsubsection{Panel Unit Root Tests}

Returning back to the unit root tests, they include among others, Levin, Lin and Chu's test (2002) [22], Harris-Tsavalis test (1999) [13], and Breitung (2000) [4]. These types of tests are all based on the assumption of having the individual time series in the panel being cross-sectional independently distributed.

Consider a simple panel-data model with a first-order autoregressive component,

$$
y_{i t}=\rho_{i} y_{i, t-1}+\delta_{i} X^{\prime}{ }_{i t}+\epsilon_{i t}
$$

Where $i=1, \ldots, N$ indexes panels; $t=1, \ldots, T$ indexes time; $y_{i t}$ is the variable being tested; and $\epsilon_{i t}$ is a stationary error term that is assumed to be mutually independent idiosyncratic disturbance. The $X_{i t}$ term can represent panel-specific means only or panel-specific means and a time trend, or nothing.

Panel unit-root tests are used to test the null hypothesis $\mathrm{H}_{0}$ : $\rho_{i}=1$ for all $i$ versus the alternative $\mathrm{H}_{\mathrm{a}}: \rho_{i}<1$. Depending on the test, $\mathrm{H}_{\mathrm{a}}$ may hold, for onei, a fraction of all $i$ or alli; the output of the respective test precisely states the alternative hypothesis. In this paper, to examine the stationarity of the variables panel models, different types of first generation panel-unit root tests have been performed, namely, HT (1999) Breitung (2000) and LLC (2002). In addition, second generation tests have been implemented whenever cross-section dependence among the panel units is detected.

(i). First Generation Panel Unit Root Tests

1) The Levin-Lin-Chu (LLC) test

The starting point for the Levin-Lin-Chu (LLC) [22] test assumes the restriction that all panels share a common autoregressive parameter. 
LLC augments the model with additional lags of the dependent variable so that $\mu_{i t}$ will be white noise with potentially heterogeneous variance across panels:

$$
\Delta y_{i t}=\alpha y_{i t-1}+\sum_{j=1}^{p} \beta_{i j} \Delta y_{i t-j}+\delta_{i} X_{i t}^{\prime}+\mu_{i t}
$$

With the assumption of having a common $(\alpha)=\rho-1$. The null and alternative hypotheses for the tests may be written as:

$$
H_{0}: \alpha=0 \text { vs } H_{1}: \alpha<1
$$

Under the null hypothesis, there is a unit root, while under the alternative, there is no unit root.

2) Harris-Tsavalis (HT) Test

Harris-Tsavalis test (1999) [13] is based on the simple assumption that all panels share the same autoregressive parameter so that $\rho_{i}=\rho$ for alli. The HT test assumes that the number of time periods, $T$, is fixed, whereas $N$ tends to infinity. The HT test is suitable for micro panel where the time dimension, $T$, is small.

The HT test statistic is established based on the OLS estimator, $\rho$ in the regression model:

$$
y_{i t}=\rho y_{i, t-1}+\delta_{i} X_{i t}+\epsilon_{i t}
$$$$
B_{n T}=\left[\left(\frac{\hat{\sigma}^{2}}{n T^{2}}\right) \sum_{i-1}^{n} \sum_{i-2}^{T-1}\left(Y_{i t-1}^{*}{ }^{2}\right)\right]^{-\frac{1}{2}}\left[(1 / \sqrt{n T})\left(\sum_{i=1}^{n} \sum_{i=2}^{T-1}\left(\Delta Y_{\mathrm{it}}{ }^{*}\right) Y_{i t-1}^{*}\right)\right]
$$

Where the term $\delta_{i} X^{\prime}{ }_{i t}$ allows for panel specific means and trends. It is assumed that $\epsilon_{i t}$ is independent and identically distributed (i.i.d) normal with constant variance across panels. Harris and Tsavalis obtained the mean and standard error of $\hat{\rho}$ for (11) under the null hypothesis,

$\mathrm{H}_{0}: \rho=1$ when neither panel-specific means nor time trends are included.

3) The Breitung Test (2000)

Breitung test as well as LLC assumes the same basic ADF specification as in regression model (3.1) where both tests augment the model with additional lags of the dependent variable so that $\varepsilon_{\text {it }}$ will be white noise. As Breitung (2000) studied the local power of the LCC, he found that the LLC suffer from a dramatic loss of power when individual specific trend is included. As such, Breitung (2000) formulated a panel unit root test statistic which corrects for the great loss of power accompanied with the LLC in the case when individual ADF tests include a trend in the specification. Within this setting, Breitung suggested the $t$-ratio for testing the null hypothesis of a common unit autoregressive root against the alternative of the stationarity of the data as follows;
Where $\widehat{\sigma}^{2}$ is a consistent estimator of $\sigma^{2}, Y_{i t}^{*}=Y_{i t-1}-$ $Y_{i 0}-\left[((t-1) / T)\left(Y_{i T}-Y_{i 0}\right)\right]$.

The Breitung test shows good power even with small datasets, although the power of the test appears to worsen when $T$ is fixed and $N$ is increased. Nevertheless, the Breitung (2000) test assumes that the error term $\varepsilon_{i t}$ is uncorrelated across both $i$ and $t$.

(ii). Second-Generation Panel Unit Root Tests

The second generation of tests relaxes the cross-sectional independence assumption. Thus, only the CIPS test will be applied in this thesis for the case when some panels are suspected to suffer from cross section dependence. Pesaran (2007) [30] suggested an easy method in dealing with the cross-sectional dependence. The procedure is based on augmenting the usual ADF regression with the lagged cross-sectional mean and its first difference to catch the cross-sectional dependence arising through a single factor model. This procedure depends on standard unit root statistics in a usual DF (or ADF) regression with the only difference being that it is augmented with cross-section averages of lagged levels and first-differences of the individual series. For the unit root null hypothesis considered, Pesaran (2007) suggested a test based on the t-ratio of the OLS estimate $\hat{\rho_{-}} i$ as in (13).

Equation (13) is called the cross-sectionally augmented Dickey-Fuller (CADF) test. If the residuals are not serially correlated, then the regression used for the ith country is given as the follow and the simple CADF regression takes the following form:

$$
\Delta y_{i t}=a_{i}+\rho_{i}^{*} y_{i, t-1}+c_{i} \bar{y}_{t-1}+d_{i} \Delta \bar{y}_{t}+\varepsilon_{i, t}
$$

Where $\bar{y}_{t}=\frac{1}{N} \sum_{i=1}^{N} y_{i, t}$, represents the average at time $t, \Delta \bar{y}_{t}=\frac{1}{N} \sum_{i=1}^{N} \Delta y_{i, t}$ and $\epsilon_{i, t}$ is the regression error.

After running this CADF regression for each unit $i$ in the panel, Pesaran averages the t-statistics on the lagged value (called CADFi) to obtain the CIPS statistic, The individual CADF statistics are used to develop a modified version of the IPS $t$-bar test denoted CIPS for Cross-sectionally Augmented (IPS) that simultaneously take account of cross-section dependence and residual serial correlation.

The CIPS test statistic takes the following from;

$$
\mathrm{CIPS}=\frac{1}{N} \sum_{i=1}^{N} C A D F_{i}
$$

Where $C A D F_{i}$ is the cross sectional augmented dickey fuller statistic for the $i_{t h}$ cross sectional unit given by t-ratio of the OLS estimate of $\rho^{*}{ }_{i}$ in the CADF regression of(13). The t-tests constructed on this regression is free of cross-sectional dependence.

\subsubsection{Panel Co-integration Analysis}

The application of cointegration examination is of significance particularly when managing non-stationary variables that may assume the presence of long run relationship.

(i). First Generation Co-integration Tests

1) Kao-Panel Cointegration Test

Considering a general panel data model as;

$$
y_{i t}=\dot{x}_{i t} \beta+Z^{\prime}{ }_{i t} \gamma_{i}+e_{i t}
$$

Kao (1999) [19] tests assume a cointegrating vector that is 
the same across all panels, which restricts $\beta_{i}=\beta$ in (15). However, Kao tests estimate panel-specific means and do not permit for a time trend, $\operatorname{so}(z)$ from (15) is always a vector of 1 's for Kao tests and $y_{i t}$ and $\dot{x}_{i t}$ are I (1) and non-cointegrated. This yields the cointegrating relationship;

$$
y_{i t}=\dot{x}_{i t} \beta+\gamma_{i}+e_{i t}
$$

Where $\gamma_{i}$ denotes panel-specific means (fixed effects) and $\beta$ is the same cointegrating vector. The null hypothesis of the Kao test is the absence of cointegration among the series. The alternative hypothesis assumes that the series in all panels are cointegrated with the same cointegrating vector.

2) Pedroni panel cointegration test $(1999,2004)$

Pedroni $(1999,2004)$ [28, 29] proposed a residual-based test that, as Kao test, depending on the Engle Granger framework. The test allow for individual fixed effects, trend term and no exogeneity requirements are imposed on the regressors of the cointegrating regressions. Pedroni (2004) presented a set of residual-based test statistics for the null of no cointegration that do not pool the slope coefficients of the regression and as such do not limit the estimated slope coefficients to be the same across members of the panel. These statistics are employed as tests for the null of no cointegration in the general case where the regressors are fully endogenous and the slope coefficients are permitted to vary across individual members of the panel. As both the dynamics and the cointegrating vector are allowed to vary across individual members of the panel, then it can be thought of the possible existence of the cointegrating relationship as indicated by the stationarity properties of the estimated residuals.

Pedroni considered the following general form of regression:

$$
y_{i t}=\alpha_{i}+\delta_{i t}+\beta_{i} x_{i t}+e_{i}
$$

where $y_{i t}$ and $x_{i t}$ are assumed to be $I(1)$ variables for each individual time series of the panel, and under the null of no co-integration the residual $e_{i t}$ is assumed to be $I$ (1), The parameters $\alpha_{i}$ and $\delta_{i t}$ are the individual specific fixed effects and deterministic trends respectively, $\beta_{i}$ is the estimated slope coefficients, which permitted to vary across individuals. The test derives seven statistics. Of these seven statistics, four are based on within - dimension, and three are based on between - dimension. For the former, the panel cointegration statistics impose a common coefficient under the alternative hypothesis which will be used here in the analysis. For the latter, the group mean cointegration statistics allow for heterogeneous coefficients.

In the case of within - dimension statistics the null hypothesis of no cointegration for the panel cointegration test is:

$$
\begin{aligned}
& H_{0}=\rho_{i}=1 \text { for all } i \\
& H_{a}=\rho_{i=} \rho<1 \text { for all } i
\end{aligned}
$$

The basic methodology is to estimate the hypothesized cointegrating relationship separately for each member of the panel and then pool the resulting residuals when constructing the panel tests for the null of no cointegration. Precisely, in the first step, the proposed cointegrating regression for each individual member of the panel in the form of (17) is estimated, including idiosyncratic intercepts or trends as the particular model warrants, to obtain the corresponding residuals. In the second step, the way in which the estimated residuals are pooled will differ among the various statistics (Pedroni, 2004). Based on the previous analysis and depending on the nature of this study that restricts the AR coefficient to be the same across the panel units, certain Pedroni statistics will be taken as a reference in deciding whether or not there exists a cointegration. These statistics are modified variance ratio (VR), modified Phillips-Perron $t$ (PP), Phillips-Perron t (PP) and Augmented Dickey-Fuller t (ADF). These tests assume that the regressors are endogenous and can be serially correlated as well. In addition, the Variance ratio test reported by Pedroni do not require modeling or accommodating for serial correlation if exists.

3) Westerlund (2005) Test

For the null hypothesis of no cointegration, Westerlund (2005) [44] derives a Variance Ratio test statistic. By default, the model uses an AR parameter that is panel specific as in (20) and the alternative hypothesis is that the series in some of the panel countries are cointegrated.

$$
y_{i t}=\dot{x}_{i t} \beta_{i}+Z^{\prime}{ }_{i t} \gamma_{i}+e_{i t}
$$

However, the possibility of restricting the AR parameter to be common across all the panel countries is provided in the alternative hypothesis. Specifically, the alternative hypothesis in this latter case restricts the $\left(\rho_{i}=\rho\right)$ in $(21)$ :

$$
\hat{e}_{i t=} \rho_{i} \hat{e}_{i t-1}+v_{i t}
$$

In fact, Westerlund presume that all of the panel countries are having individual slope coefficients and hence expect a panel-specific cointegrating vectors as in (20). The VR test statistics are calculated through examining for a unit root in the predicted residuals using the DF regression as specified in (21).

(ii). Second Generation Panel Cointegration Tests / Error Correction Based Cointegration Test

Westerlund (2007) [45] established four new panel cointegration tests which are based on structural rather than residual dynamics and, hence, do not impose any common-factor restriction. The goal of the test is to examine the null hypothesis of no cointegration by concluding whether the error-correction term in a panel error-correction model is equal to zero. These tests are applicable in both cases of the existence and non-existence of cross-sectional dependency. Bootstrap distribution is used when cross-sectional dependency occurs while standard asymptotically normal distribution is used when it does not exist (Westerlund, J., 2007).

The tests depends on specific assumptions that build up the essential conditions required for the cointegration test, yet 
and in point of fact, the only really necessary prerequisite is that the regressors contained in $x_{i t}$ are weakly exogenous. Specifically, weak exogeneity guarantees that a test for no cointegration can be executed as a test for no error correction in (22) as the follows:

$$
\Delta y_{i t}=\delta_{i}^{\prime} d_{t}+\alpha_{i}\left(y_{i t-1}-\beta_{i}^{\prime} x_{i t-1}\right)+\sum_{j=1}^{p i} \alpha_{i j} \Delta y_{i t-j}+\sum_{j=0}^{p i} \gamma_{i j} \Delta x_{i t-j}+e_{i t}
$$

Where $t=1, \ldots, T$ and $i=1, \ldots, N$ indicate the time-series and cross-sectional units, respectively. $d_{t}$ Contains the deterministic components, for which there are three cases; the first case, $d_{t}=0$ so that (3.24) has no deterministic terms, the second case, $d_{t}=1$ so that $\Delta y_{i t}$ is generated with a constant and finally in the third case, $d_{t}=(1, \mathrm{t})$ so that $\Delta y_{i t}$ is generated with both a constant and a trend. $\alpha_{i}$ Represents the error correction parameter and the error correction term is presented by $\left(y_{i t-1}-\beta_{i}^{\prime} x_{i t-1}\right)$. On the other hand side, for simplicity, (22) can be reparametrized as follows:

$$
\Delta y_{i t}=\delta_{i}^{\prime} d_{t}+\alpha_{i} y_{i t-1}+\lambda_{i}^{\prime} x_{i t-1}+\sum_{j=1}^{p i} \alpha_{i j} \Delta y_{i t-j}+\sum_{j=0}^{p i} \gamma_{i j} \Delta x_{i t-j}+e_{i t}
$$

Where $\lambda_{i}^{\prime}=-\alpha_{i} \beta_{i}^{\prime}$ The parameter $\alpha_{i}$ specifies the speed of adjustment at which the system corrects back to the equilibrium relationship $\left(y_{i t-1}-\beta_{i}^{\prime} x_{i t-1}\right)$ after a sudden shock. $\alpha_{i}$ Can be estimated using least squares and hence can be used to provide a valid test of $\mathrm{H}_{0}$ vs. $\mathrm{H}_{1}$. If $\alpha_{i}$ <zero, then there is error correction suggesting the presence of cointegration between $y_{i t}$ and $x_{i t}$, whereas if $\alpha_{i}=$ zero, then, the error correction is absent and there is no cointegration. This suggests that the null hypothesis of no co-integration for cross-sectional unit $i$ can be implemented as a test of ${ }^{1} \mathrm{H}_{0}: \alpha_{i}=$ Zero.

Based on this idea, four new statistics are being implemented which include panel and group mean statistics. Panel statistics are the ones that depend on pooling the information regarding the error correction along the cross-sectional dimension of the panel.

Thus, and in conclusion, testing for cointegration can be made through either first generation or second-generation approaches. The second-generation tests of the error correction based test requires only weak exogeneity and thus still can be applicable for the cases of endogenous variables. If no cross sectional-correlation problem is detected then, the first-generation tests will be used and the most appropriate of them is the Kao (1999) cointegration test, yet the other tests are going to be conducted as robustness check. The first generation tests are also applicable in case of cross section dependence after mitigating the impact of cross-sectional dependence.

\subsubsection{Panel VAR Analysis}

In general, a dynamic relationship is characterized by the presence of a lagged dependent variable among the regressors. Assuming a basic model that includes only two variables,

$$
\begin{array}{r}
L Y_{i t}=\alpha_{0}+\lambda_{1,1} L Y_{i t-1}+\lambda_{1,2} L X_{i t-1} \\
1 \ldots \ldots, T
\end{array}+u_{i t} i=1, \ldots \ldots, N, t=
$$

Where $i=1 \ldots, N$ (cross-sectional dimension) and $t=1 \ldots, T$ (time dimension). $\lambda_{1}$ Is a scalar; $Y_{i t}$ is a $(1 x k)$ vector of dependent variables, $X_{i t}$ is a $(1 x l)$ vector of regressors taking into consideration that the model of interest has no exogenous variables. In applying the VAR procedure to panel data, there is a need to impose the restriction that the

\footnotetext{
${ }^{1}$ Although the test is heterogeneous, but homogeneous second-generation pane co-integration test was not available.
}

underlying structure is the same for each cross-sectional unit. However and in reality, this constraint is likely to be violated, thus, one way to overcome such a restriction on parameters is by allowing "individual heterogeneity" in the levels of the variables by introducing fixed effects, denoted by $\left(u_{i}\right)$ in the model.

Assuming that $u_{i t}$ consists of the following;

$$
u_{i t}=\mu_{i}+v_{i t}
$$

$u_{i t}$ Is composed of the two error components $\mu_{i}$ as the unobservable individual effects and $v_{i t}$ is the remainder error term and $\mu_{i} \sim \operatorname{IID}\left(0, \sigma_{\mu}^{2}\right)$ and $v_{i t} \sim \operatorname{IID}\left(0, \sigma_{\mu}^{2}\right)$ independent of each other and among themselves.

In order to estimate the dynamic panel data regression described in (24) and (25), it can be found that it is characterized by two sources of persistence over time. First, due to the autocorrelation stemming from the presence of a lagged dependent variable among the regressors. Second, because of the individual effect characterizing the heterogeneity among the individuals. These two sources of persistence render different estimators to be inadequate in estimating the PVAR dynamic model and that's why the approach of Blundell \& Bond (1998) [3] which is known as 'system' GMM (SYS-GMM) is going to be used which makes use of both 'level' and 'difference' GMM.

Despite what its name implies, a 'system' GMM, deals with the data system as a single-equation problem since the same linear functional relationship is believed to apply in both the transformed and untransformed variables as:

$$
\left(\begin{array}{c}
\Delta y \\
y
\end{array}\right)=\alpha\left(\begin{array}{c}
\Delta y_{t-1} \\
y_{t-1}
\end{array}\right)+\beta\left(\begin{array}{c}
\Delta X_{t-1} \\
X_{t-1}
\end{array}\right)+\left(\begin{array}{c}
\Delta u \\
u
\end{array}\right)
$$

The system GMM eliminate the fixed effect through some kind of transformation other that differencing called 'forward mean differencing or orthogonal deviations' (the Helmert procedure). In this procedure, to remove the fixed effects, all variables in the model are transformed in deviations from forward means.

Let $y_{i t}^{m}$ and $u_{i t}^{m}$ denote a variable and an error term, respectively in two vectors;

$$
y_{i t}=\left(y_{i t}^{1}, y_{i t}^{2} \ldots \ldots, y_{i t}^{M}\right)
$$

And

$$
e_{i t}=\left(e_{i t}^{1}, e_{i t}^{2}, \ldots \ldots, e_{i t}^{M}\right)
$$


The means obtained from the future values of $y_{i t}^{m}$ and $u_{i t}^{m}$ are equal to;

$$
\begin{aligned}
& \bar{y}_{i t}^{m}=\sum_{s=t+1}^{T_{i}} \frac{y_{i s}^{m}}{\left(T_{i-1}\right)} \\
& \bar{u}_{i t}^{m}=\sum_{S=t+1}^{T_{i}} \frac{u_{i s}^{m}}{\left(T_{i-1}\right)}
\end{aligned}
$$

Where $T_{i}$ is the last period of data available for a given country series. The transformed variable and error term can be written as:

$$
\tilde{y}_{i t}^{m}=\delta_{i t}\left(y_{i t}^{m}-\bar{y}_{i t}^{m}\right)
$$

And

$$
\tilde{u}_{i t}^{m}=\delta_{i t}\left(u_{i t}^{m}-\bar{u}_{i t}^{m}\right)
$$

Where,

$$
\delta_{i t}=\sqrt{\frac{T_{i-t}}{T_{i-t+1}}}
$$

However, the last year of data cannot be calculated, this is because there are no future values for the construction of the forward means. This transformation is in fact an orthogonal deviation in the sense that each observation is expressed as a deviation from average future observations. According to Roodman (2009) [33], one advantage of the forward means differencing over the first-difference procedure is that it has the virtue of preserving sample size in panels with gaps. The first-difference procedure has the deficiency of magnifying gaps in unbalanced panels. This technique enables the use of lagged values of regressors as instruments. Then, the transformed model becomes:

$$
\tilde{y}_{i t}=\alpha_{1} \tilde{y}_{i t}+\tilde{e}_{i t}
$$

Where

$$
\tilde{y}_{i t}=\left(\tilde{y}_{i t}^{1}, \tilde{y}_{i t}^{2}, \ldots \ldots, \tilde{y}_{i t}^{M}\right)
$$

And

$$
\tilde{u}_{i t}^{m}=\left(\tilde{u}_{i t}^{1}, \tilde{u}_{i t}^{2}, \ldots \ldots ., \tilde{u}_{i t}^{M}\right)^{\prime}
$$

If the original errors are not auto correlated and are characterized by a constant variance, the transformed errors should exhibit similar properties. Thus, this transformation preserves homoscedasticity and does not induce serial correlation.

However, if serial correlation in the error is tested and found to be present, then suitably longer lags of the regressors as instruments significantly reduces this problem. In short, the basic idea of the difference GMM is to write the regression equation as a dynamic panel data model, take first-differences to remove unobserved time-invariant country-specific effects, and then instrument the right-hand-side variables in the first-differenced equations using levels of the series which lagged two periods or more, under the assumption that the time-varying disturbances in the original level equations are not serially correlated. On the contrary, the system GMM estimator combines the standard set of equations in first-differences and use lagged levels as instruments, with an additional set of equations in levels that use lagged first-differences as instruments. Though the levels of $y_{i t}$ are necessarily correlated with the individual-specific effects $\left(\mu_{i}\right)$, the first-differences $\Delta y_{i t}$ are not correlated with $\mu_{i}$, permitting lagged first-differences to be used as instruments in the level equations.

To the best of my knowledge, this kind of investigation has not been done until the date of the day with the previously mentioned set of variables for the whole globe being clustered into four income panels and this study is the first one that uses PVAR approach in a system GMM framework for this selected panel countries.

\section{Empirical Results}

In this paper, the results will start with some descriptive statistics for the four panel's models variables as shown through tables 2 to 5. After that the results of panel unit root tests, panel cointegration tests and panel VAR's will be presented. All these tests will be conducted after examining for the presence or absence of cross section correlation between the panel units.

\subsection{Variables Properties}

Before conducting any unit root tests, the number of lags used for each variable should be firstly determined which is done according to an information selection criterion. The AIC criterion is the one that is going to be used for the four income panels. Moreover, descriptive statistics for the four panels are illustrate through Tables 2 to 5 as seen below where the sample period is from 1990 to 2015, including 26 years.

According to tables 2 to 4 of the high income and lower middle income countries, With respect to the Jarque-Bera (1980) test (JB), all of the variables results of JB tests reject the null hypothesis of $\mathrm{H} 0$ that the data are sampled from a normal distribution, indicating that the data are not sampled from a normal distribution. As previously mentioned, the log transformation of the data improves the normality of the distribution. With respect to the standard deviation and for the four panels, it can be said that all of the variables have high values of standard deviation except for the HDI. High values for variation indicating that data is highly spread out which adds more variability for the variables leading it to be more precise.

Table 2. High Income Countries Summary statistics.

\begin{tabular}{lllllll}
\hline & PCO2 & REC & HDI & EI & FD & TO \\
\hline Mean & 9.189 & 14.18 & 0.837 & 4.618 & 93.53 & 103.68 \\
Maximum & 35.91 & 61.37 & 0.948 & 11.76 & 253.2 & 442.62 \\
Minimum & 1.089 & 0.000 & 0.659 & 1.488 & 12.89 & 16.013 \\
J-B & 664.4 & 239.8 & 39.18 & 237.4 & 57.80 & 982.27 \\
Prob. & $(0.000)$ & $(0.000)$ & $(0.000)$ & $(0.000)$ & $(0.00)$ & $(0.00)$ \\
S. D. & 5.388 & 15.10 & 0.060 & 1.536 & 47.43 & 84.522 \\
No of Obs. & 832 & 832 & 832 & 832 & 832 & 832 \\
\hline
\end{tabular}

Source: Author's own calculations. Note: Numbers between parentheses refer to the probability of the test statistics and JB is the Jarque-Bera test. 
Table 3. Upper Middle Income Countries Summary statistics.

\begin{tabular}{lllllll}
\hline & PCO2 & REC & HDI & FD & EI & TO \\
\hline Mean & 2.91 & 26.39 & .672 & 43.01 & 5.08 & 77.04 \\
Max. & 9.97 & 88.09 & .82 & 166.50 & 29.09 & 274.97 \\
Min. & .02 & .05 & .47 & .87 & 1.9 & 13.7 \\
J-B & 223.2 & 106.2 & 5.9 & 363.6 & 8516.0 & 425.4 \\
Prob. & $(0.000)$ & $(0.00)$ & $(0.01)$ & $(0.00)$ & $(0.00)$ & $(0.00)$ \\
S. D. & 2.1 & 21.1 & 0.0 & 35.0 & 2.8 & 40.0 \\
No of Obs. & 806 & 806 & 806 & 806 & 806 & 806 \\
\hline
\end{tabular}

Source: Author's own calculations. Note: Numbers between parentheses refer to the probability of the test statistics, JB is the Jarque-Bera test.

Table 4. Lower Middle Income Countries Summary Statistics.

\begin{tabular}{lllllll}
\hline Statistic & HDI & REC & EI & PCO2 & FD & TO \\
\hline Mean & 0.544 & 45.90 & 6.697 & 1.320 & 31.04 & 74.338 \\
Max. & 0.747 & 88.44 & 26.699 & 13.447 & 114.7 & 189.25 \\
Min. & 0.332 & 0.600 & 2.302 & 0.049 & 0.962 & 11.087 \\
J-B & 23.18 & 34.35 & 1499.8 & 5365 & 212.5 & 49.995 \\
Prob. & $(0.00)$ & $(0.00)$ & $(0.00)$ & $(0.00)$ & $(0.00)$ & $(0.00)$ \\
S. D. & 0.096 & 24.88 & 4.169 & 1.738 & 20.27 & 31.379 \\
No of Obs. & 598 & 598 & 598 & 598 & 598 & 598 \\
\hline
\end{tabular}

Source: Author's own calculations. Note: Numbers between parentheses refer to the probability of the test statistics, JB is the Jarque-Bera test.

Table 5. Low Income Countries Summary statistics.

\begin{tabular}{lllllll}
\hline & PCO2 & REC & EI & HDI & FD & TO \\
\hline Mean & 0.164 & 82.47 & 10.44 & 0.3963 & 12.254 & 56.762 \\
Maximum & 0.817 & 97.29 & 50.13 & 0.590 & 64.74 & 156.8 \\
Minimum & 0.020 & 48.11 & 2.056 & 0.189 & 1.603 & 19.68 \\
J-B & 653.9 & 68.80 & 3315. & 4.808 & 1696. & 371.6 \\
Prob. & $(0.0)$ & $(0.00)$ & $(0.00)$ & $(0.09)$ & $(0.0)$ & $(0.0)$ \\
S. D. & 0.133 & 12.04 & 6.736 & 0.079 & 9.589 & 25.62 \\
No of Obs. & 390 & 390 & 390 & 390 & 390 & 390 \\
\hline
\end{tabular}

Source: Author's own calculations. Note: Numbers between parentheses refer to the probability of the test statistics, and JB is the Jarque-Bera test.

\subsection{Lag Order Selection}

Due to the relatively small period applied in this study, only three lags are allowed to select from and will be set as a maximum lag order for the AIC criterion. Moreover, according to Wooldridge, J. M., (2016), he mentioned that when the sample size is small and the data is annual, then one or two lags are enough in order not to lose degrees of freedom.

According to the results of tables 6 to 9, different number of lags are being selected for the variables as presented in the tables ranging from one lag to three lags. Lags selected will be used for the panel unit root test and cross section dependence tests.
Table 6. High Income Countries.

\begin{tabular}{lllllll}
\hline Lags & LPCO2 & HDI & LREC & LFD & LTO & LEI \\
\hline 1 & $-1585^{*}$ & $-6521^{*}$ & 729 & $-1267^{*}$ & $-1993^{*}$ & $-2328^{*}$ \\
2 & -1527 & -6265 & 723 & -123 & -1908 & -2252 \\
3 & -1465 & -5994 & $279^{*}$ & -1194 & -1814 & -2148 \\
\hline
\end{tabular}

Source: Author's own calculations. Notes:* indicates lag order selected.

Table 7. Upper Middle Income Countries.

\begin{tabular}{lllllll}
\hline Lags & LPCO2 & HDI & LREC & LFD & LTO & LEI \\
\hline 1 & -691 & -5695 & $-950^{*}$ & -364 & -1098 & $-1967^{*}$ \\
2 & -1174 & $-5796^{*}$ & -914 & -391 & -1140 & -1899 \\
3 & $-1302^{*}$ & -5689 & -941 & $-535^{*}$ & $-1263^{*}$ & -1829 \\
\hline
\end{tabular}

Source: Author's own calculations. Notes:* indicates lag order selected.

Table 8. Lower Middle Income countries.

\begin{tabular}{lllllll}
\hline Lags & LPCO2 & HDI & LREC & LFD & LTO & LEI \\
\hline 1 & $-874^{*}$ & $-4513^{*}$ & $-1489.7^{*}$ & -190.45 & -720.0 & $-1483.0^{*}$ \\
2 & -844 & -4504 & -1412.1 & $-221.8^{*}$ & $-744.3^{*}$ & -1420.1 \\
3 & -799 & -4408 & -1348.75 & -209 & -730.4 & -1356.8 \\
\hline
\end{tabular}

Source: Author's own calculations. Notes:* indicates lag order selected.

Table 9. Low Income Countries.

\begin{tabular}{lllllll}
\hline Lags & LPCO2 & HDI & LREC & LFD & LTO & LEI \\
\hline 1 & $-330.5^{*}$ & $-2674.5^{*}$ & $-1450.0^{*}$ & -163.74 & -284.0 & $-711.765^{*}$ \\
2 & -314.51 & -2669.19 & -1381.73 & $-168.2^{*}$ & $-288.0^{*}$ & -671.05 \\
3 & -294.98 & -2598.40 & -1314.33 & -161.24 & -271.29 & -644.67 \\
\hline
\end{tabular}

Source: Author's own calculations. Notes:* indicates lag order selected.

\subsection{Cross-sectional Dependence Results}

In this section results of examining for cross sectional correlation among the four income panels units are going to be displayed through tables 10 to 13 .

According to the results presented in Table 10, it can be inferred that all of the variables suffer from cross sectional correlation in the high income countries panel where the null hypothesis is rejected at the $1 \%$ level of significance and thus second-generation tests for testing unit root and co-integration should be applied. Also and presented in table 11, it can be shown that most of the variables suffer from cross sectional correlation where the null hypothesis is rejected at the $1 \%$ and $5 \%$ levels of significance. At the 5\% level of significance, only renewable energy consumption cannot reject the null hypothesis, therefore, as most of the variables suffer from cross sectional correlation, then, second-generation tests for examining unit root and co-integration should be implemented.

Table 10. The Pesaran (CD) and Bresuch and Pagan (LM) Tests with intercept-High Income Countries.

\begin{tabular}{lll}
\hline With Intercept & & \\
\hline Variables & Pesaran CD-statistic (P-value) & Bresuch and Pagan LM-Statistic (p-value) \\
\hline LPCO2 & $9.464(0.0000)$ & $851.1(0.0000)$ \\
LREC & $4.025(0.0001)$ & $572.3(0.0099)$ \\
LEI & $15.79(0.0000)$ & $966.7(0.0000)$ \\
LFD & $2.664(0.0077)$ & $837(0.0000)$ \\
LTO & $46.27(0.0000)$ & $3199(0.0000)$ \\
HDI & $4.009(0.0001)$ & $654.3(0.0000)$ \\
\hline
\end{tabular}

Source: Author's own calculations. Notes: (1) P-values are in parenthesis and (2) The null hypothesis is cross section independence. 
Table 11. The Pesaran (CD) and Bresuch and Pagan (LM) Tests with intercept-Upper Middle Income Countries.

\begin{tabular}{lll}
\hline \multicolumn{2}{l}{ With Intercept } \\
\hline Variables & $\begin{array}{l}\text { Pesaran CD-statistic } \\
\text { (P-value) }\end{array}$ & $\begin{array}{l}\text { Bresuch and Pagan } \\
\text { LM-Statistic (p-value) }\end{array}$ \\
\hline LPCO2 & $2.642(0.0082)$ & $484.8(0.2540)$ \\
LREC & $-.0703(0.9440)$ & $478.5(0.3225)$ \\
LEI & $2.189(0.0286)$ & $508.1(0.0817)$ \\
LFD & $4.517(0.0000)$ & $517.1(0.0475)$ \\
LTO & $13.37(0.0000)$ & $808.2(0.0000)$ \\
HDI & $3.436(0.0006)$ & $575.8(0.0003)$ \\
\hline
\end{tabular}

Source: Author's own calculations. Notes: (1) P-values are in parenthesis and (2) The null hypothesis is cross section independence.

With respect to the results presented in table 12 , it can be observed that at the 5\% level of significance, Bresuch and Pagan LM statistic couldn't reject the null hypothesis of cross sectional independence for both of energy intensity and HDI only. This means that all of the other variables suffer from cross sectional correlation at the $1 \%$ significance level. The results here as mentioned before will rest more on Bresuch and Pagan LM-test concluding that there exists some degree of correlation among the panel units and hence second generation tests should be applied.

Table 12. The Pesaran (CD) and Bresuch and Pagan (LM) Tests with Intercept-Lower Middle Income Countries.

\begin{tabular}{lll}
\hline \multicolumn{2}{l}{ With Intercept } & \\
\hline Variables & $\begin{array}{l}\text { Pesaran CD-statistic } \\
\text { (P-value) }\end{array}$ & $\begin{array}{l}\text { Bresuch and Pagan } \\
\text { LM-Statistic (p-value) }\end{array}$ \\
\hline LPCO2 & $3.993(0.0001)$ & $3.591(0.0003)$ \\
LREC & $2.389(0.0169)$ & $3.21(0.0013)$ \\
LEI & $3.269(0.0011)$ & $275.3(0.1606)$ \\
LFD & $1.861(0.0627)$ & $347.8(0.0001)$ \\
LTO & $15.97(0.0000)$ & $592.2(0.0000)$ \\
HDI & $3.335(0.0009)$ & $263.1(0.3189)$ \\
\hline
\end{tabular}

Source: Author's own calculations. Notes: (1) P-values are in parenthesis and (2) The null hypothesis is cross section independence.

Finally and as shown in table 13, according to the LM statistic, renewable energy consumption, energy intensity and financial development cannot reject the null hypothesis at the 5\% level while the per capita $\mathrm{CO}_{2}$ emissions and trade openness cannot reject it at the $1 \%$ level. Consequently and depending more on the LM statistic, it can be said that the majority of the variables cannot reject the null hypothesis referring to the absence of correlation between the panel units. Hence, first generation tests for testing stationarity are going to be implemented and depend on it more in addition to second-generation tests for the sake of increasing accuracy.

Table 13. The Pesaran (CD) and Bresuch and Pagan (LM) Tests-Low Income Countries.

\begin{tabular}{lll}
\hline \multicolumn{2}{l}{ With Intercept } \\
\hline Variables & $\begin{array}{l}\text { Pesaran CD-statistic } \\
\text { (P-value) }\end{array}$ & $\begin{array}{l}\text { Bresuch and Pagan } \\
\text { LM-Statistic (p-value) }\end{array}$ \\
\hline LPCO2 & $4.86(0.0000)$ & $136.9(0.0198)$ \\
LREC & $.1639(0.8698)$ & $108.3(0.3939)$ \\
LEI & $-.2295(0.8185)$ & $91.67(0.8200)$ \\
LFD & $2.607(0.0091)$ & $104.3(0.5014)$ \\
LTO & $1.946(0.0517)$ & $135.4(0.0246)$ \\
HDI & $6.071(0.0000)$ & $144.9(0.0060)$ \\
\hline
\end{tabular}

Source: Author's own calculations. Notes: (1) P-values are in parenthesis and (2) The null hypothesis is cross section independence.

\subsection{Panel Unit Root Tests}

In this section first and second generation panel unit root tests are going to be presented for the four income panels variables to avoid spurious regression. Table 14 presents the first-generation panel unit root tests considering the cross-section dependence problem. With respect to HT (1999), it has a more has favorable power properties for relatively large $N$ greater than 25 as in this analysis. Accordingly, for Breitung, the results conclude that all the variables are non-stationary, have unit root, at level at the $5 \%$ level of significance, except for the renewable energy consumption at the $1 \%$ level of significance. With respect to HT (1999), the per capita $\mathrm{CO}_{2}$ emissions tends to be stationary at level for both specifications as well as renewable energy consumption and the energy intensity variables.

Table 14. First generation panel unit root tests; Breitung (2000), HT (1999) and CIPS (2007)-High Income Countries Panel.

\begin{tabular}{|c|c|c|c|c|c|c|}
\hline \multirow{3}{*}{$\begin{array}{l}\text { Specification } \\
\text { Tests } \\
\text { Variables }\end{array}$} & \multicolumn{6}{|c|}{ With intercept } \\
\hline & \multicolumn{2}{|c|}{ Breitung (2000) } & \multicolumn{2}{|c|}{ HT (1999) } & \multicolumn{2}{|c|}{ CIPS (2007) } \\
\hline & Level & $\Delta$ & Level & $\Delta$ & Level & $\Delta$ \\
\hline LPCO2 & -0.205 & $-19.66 * * *$ & $0.776^{* * *}$ & - & -2.156 & $-4.766 * *$ \\
\hline LREC & 3.281 & $-11.73 * * *$ & 0.885 & $0.016 * * *$ & -2.325 & $-4.183 * * *$ \\
\hline LEI & 2.725 & $-19.40 * * *$ & 0.873 & $-0.151 * * *$ & $-2.509 * * *$ & - \\
\hline LFD & -0.371 & $-15.51 * * *$ & 0.901 & $0.143 * * *$ & -1.802 & $-3.814 * *$ \\
\hline LTO & -1.047 & $-16.33 * * *$ & 0.904 & $0.210 * * *$ & -1.724 & $-3.582 * *$ \\
\hline
\end{tabular}

Source: Author's own calculations. (1) The null hypothesis is that "Panels contain unit roots'. (2) The lambda statistic is reported for the Breitung tests and the rho statistic is reported for the HT test. (3) The number of panel units $=32$ and periods $=26$ for the variables in levels and 25 years for the variables in difference. (4) All of the tests have subtracted the cross sectional means to mitigate cross section dependence problem. (5) The critical values for the CIPS statistic is- $2.08,-2.16$ and-2.3 for variables in level.

For a better treatment to the problem of cross sectional dependence, the analysis should depends more on the CIPS (2007) test. Thus, the CIPS test, with respect to table 14, concluded that all of the variables are stationary at first difference at the $5 \%$ and $1 \%$ levels of significance, except for the energy intensity variable only. Accordingly, it can be 
concluded that with reference to most of the tests applied, that most of the variables are stationary at first difference and it is preferred to proceed by testing for co-integration relationships among the variables, assuming that the co-integrating equations have only intercept.

Table 15. First generation panel unit root tests; The Breitung (2000), HT (1999) and CIPS (2007)-Upper Middle Income Countries Panel.

\begin{tabular}{lllllll}
\hline Specification & \multicolumn{2}{l}{ With intercept } \\
\hline Tests & \multicolumn{2}{l}{ Breitung (2000) } & \multicolumn{2}{l}{ HT (1999) } & \multicolumn{2}{l}{ CIPS (2007) } \\
\hline Variables & \multicolumn{2}{l}{ Level } & $\Delta$ & Level & $\Delta$ & \multicolumn{2}{l}{ Level } & $\Delta$ \\
\hline LPCO2 & 0.75 & $-12 * * *$ & $0.57 * *$ & - & $-2.7 * *$ & - \\
LREC & -0.3 & $-17 * * *$ & 0.85 & $0.0 * * *$ & -2.0 & $-4.4 * *$ \\
LEI & 2.10 & $-17 * * *$ & 0.89 & $-0.0 * * *$ & -2.1 & $-5.0 * * *$ \\
LFD & $-2.6 * *$ & - & $0.81 * *$ & - & -1.9 & $-3.9 * *$ \\
LTO & -0. & $-13 * * *$ & $0.79 * *$ & - & -2.3 & $-4.3 * * *$ \\
HDI & -0.6 & $-10 * * *$ & 0.90 & $0.2 * * *$ & -1.98 & $-3.8 * *$ \\
\hline
\end{tabular}

Source: Author's own calculations. (1) The null hypothesis is that "Panels contain unit roots'. (2) The lambda statistic is reported for the Breitung tests and the rho statistic is reported for the HT test. (3) the number of panel units $=31$ and periods $=26$ for the variables in levels and 25 years for the variables in difference and (4) all of the tests have subtracted the cross sectional means to mitigate cross section dependence problem. (5) The critical values for the CIPS statistic is--2.08,-2.16 and-2.3 for variables in level.

Table 15 presents the first-generation panel unit root tests considering the cross-section dependence problem where demeaning has been performed for all of the examined time series. Accordingly, for Breitung (2000), only financial development is found to be stationary at level while all of the other variables are stationary at first difference. HT (1999) illustrates that the per capita $\mathrm{CO}_{2}$ emissions, financial development and trade openness are stationary at level while the other variables are stationary at first difference. The CIPS test for both cases concluded that all of the variables are stationary at first difference at the $5 \%$ and $1 \%$ levels of significance, except for the per capita $\mathrm{CO}_{2}$ emissions variable. Accordingly, it can be concluded that with reference to most of the tests applied, that most of the variables are stationary at first difference for the upper middle income countries panel and it is preferred to proceed by testing for co-integration relationships among the variables, assuming that the co-integrating equations have only intercept.

With respect the lower middle income countries panel, as the time dimension $N$ grows more slower than the cross-sectional dimension $T$, then the LLC (2002) panel unit root test will be more suitable to be applied than the HT (1999) in this panel. Table 16 presents the first-generation panel unit root tests considering the cross-section dependence problem for both specification. With respect to LLC (2002), only the financial development and HDI can be seen to be stationary at level at the $1 \%$ level of significance while all of the other variables are considered to be $I$ (1). Additionally, Breitung (2000) gives the same results concluding that all of the variables are stationary at first difference at the $5 \%$ level of significancehe CIPS test concluded that all of the variables are stationary at first difference at the $5 \%$ and $1 \%$ levels of significance. Accordingly, it can be concluded that with reference to most of the tests applied, that most of the variables are stationary at first difference and it is preferred to proceed by testing for co-integration relationships among the variables, assuming that the co-integrating equations have only intercept.

Table 16. First generation panel unit root tests; The Breitung (2000) and LLC (2002)-Lower Middle Income Countries.

\begin{tabular}{|c|c|c|c|c|c|c|}
\hline \multirow{3}{*}{$\begin{array}{l}\text { Specification } \\
\text { Tests } \\
\text { Variables }\end{array}$} & \multicolumn{6}{|c|}{ With intercept } \\
\hline & \multicolumn{2}{|c|}{ LLC (2002) } & \multicolumn{2}{|c|}{ Breitung (2000) } & \multicolumn{2}{|c|}{ CIPS (2007) } \\
\hline & Level & $\Delta$ & Level & $\Delta$ & Level & $\Delta$ \\
\hline LPCO2 & -1.3 & $-15 * * *$ & -0.0 & $-16 * * *$ & -2.0 & $-5.1 * *$ \\
\hline LREC & -1.2 & $-13 * * *$ & 3.1 & $-15 * * *$ & -1.7 & $-4.2 * *$ \\
\hline LEI & -1.2 & $-14 * * *$ & 1.0 & $-15 * * *$ & -1.9 & $-4.6 * *$ \\
\hline LFD & $-2.9 * * *$ & - & -1.2 & $-11 * * *$ & -2.1 & $-3.9 * *$ \\
\hline LTO & 0.7 & $-16 * * *$ & -1.0 & -13 & -2.3 & $-4.6 * * *$ \\
\hline HDI & $-2.8 * * *$ & - & 1.0 & -10 & -1.6 & $-3.5 * *$ \\
\hline
\end{tabular}

Source: Author's own calculations. (1) The null hypothesis is that "Panels contain unit roots'. (2) The t-statistic is reported for the LLC test and the lambda statistic is reported for Breitung test.(3) the number of panel units $=23$ and periods $=26$ for the variables in levels and 25 years for the variables in difference and (4) all of the tests have subtracted the cross sectional means to mitigate cross section dependence problem. (5) The critical values for the CIPS statistic is--2.07,-2.15 and-2.3 for variables in level.

Finally, low income countries panel will make use of the LLC (2002) and Breitung (2000) as well. With respect to Table 17, LLC (2002) shows that all of the variables are stationary at first difference at the $5 \%$ levels of significance and only trade openness is stationary at first difference at the $1 \%$ level. Breitung (2000) shows that all of the variables are $I$ (1) at the 5\% level. Also, with regard to CIPS (2007) test, it can be seen that the trade openness variable is the only one that is stationary at level at the $1 \%$ level of significance. With respect to all other variables, they are seen to be stationary at first difference at the 5\% level. Accordingly, it can be concluded that with reference to most of the tests applied, that most of the variables are stationary at first difference and it is preferred to proceed by testing for co-integration relationships among the variables, assuming that the co-integrating equations have only intercept

Table 17. First generation panel unit root tests; The Breitung (2000) and LLC (2002)-Low Income Countries.

\begin{tabular}{|c|c|c|c|c|c|c|}
\hline \multirow{3}{*}{$\begin{array}{l}\text { Specification } \\
\text { Tests } \\
\text { Variables } \\
\end{array}$} & \multicolumn{6}{|c|}{ With intercept } \\
\hline & \multicolumn{2}{|c|}{ LLC (2002) } & \multicolumn{2}{|c|}{ Breitung (2000) } & \multicolumn{2}{|c|}{ CIPS (2007) } \\
\hline & Level & $\Delta$ & Level & $\Delta$ & Level & $\Delta$ \\
\hline LPCO2 & 0.08 & $-11.5^{* * *}$ & 0.3 & $-12.6 * * *$ & -1.4 & $-4.6 * *$ \\
\hline LREC & 0.28 & $-11.1 * * *$ & 2.2 & $-12.0 * * *$ & -2.0 & $-4.6 * *$ \\
\hline LEI & -0.68 & $-11.1 * * *$ & 1.3 & $-11.7 * * *$ & -1.3 & $-3.9 * *$ \\
\hline LFD & 0.48 & $-12.3 * * *$ & 0.9 & $-10.0 * * *$ & -1.9 & $-4.6 * *$ \\
\hline LTO & -2.18 & $-14.6 * * *$ & -1.0 & $-11.1 * * *$ & $-2.4 * * *$ & - \\
\hline HDI & 2.18 & $-3.6 * * *$ & 4.0 & $-5.6 * * *$ & -1.8 & $-3.6 * *$ \\
\hline
\end{tabular}

Source: Author's own calculations. (1) The null hypothesis is that "Panels contain unit roots'. (2) The t-statistic is reported for the LLC test and the lambda statistic is reported for Breitung test, and (3) the number of panel units $=15$ and periods $=26$ for the variables in levels and 25 years for the variables in difference. (4) The critical values for the CIPS statistic is-2.07,-2.17 and-2.34 for variables in level. 


\subsection{Panel Co-integration Tests}

Since most of the variables have proved themselves to be stationary at first difference, then first and second generation panel co-integration tests are going to be presented for the four income panels variables to investigate whether there exists long term, relationships between the variables. First generation tests are going to be firstly implemented and then followed by second generation tests for each panel taking into consideration that the HDI is the dependent variable.

Table 18. Results of First generation Panel Co-integration Tests -High Income Countries Panel.

\begin{tabular}{|c|c|c|c|c|c|c|c|c|}
\hline \multirow{2}{*}{$\begin{array}{l}\text { Cointegration } \\
\text { Test-Intercept }\end{array}$} & \multirow{2}{*}{\multicolumn{2}{|c|}{ Kao Test }} & \multirow[b]{3}{*}{ Modified DF } & \multirow{2}{*}{\multicolumn{4}{|c|}{$\begin{array}{l}\text { Pedroni Test } \\
\text { H1: common }\end{array}$}} & \multirow{3}{*}{$\begin{array}{l}\text { Westerlund } \\
\text { Test } \\
\text { VR } \\
\end{array}$} \\
\hline & & & & & & & & \\
\hline Test Statistic & ADF & DF & & Modified VR & Modified PP & Panel PP & Panel ADF & \\
\hline HDI & 1.408 & 0.583 & 1.046 & $-5.204 * * *$ & $2.903 * * *$ & -0.836 & -0.775 & 0.032 \\
\hline
\end{tabular}

Source: Author's own calculations. Note (1) PP=Phillips-Perron; ADF=Augmented Dickey Fuller, VR=Variance Ratio. (2) Automatic lag selection, with maximum lags set to be three, is based on AIC criterion and selected 1 lag for the Kao test and 2 lags for Pedroni (3) the null hypothesis is no co-integration assuming the same AR parameter across all panels.

Table 18 shows the results of the first-generation panel cointegration assuming specification with intercept only, all of the statistics of Kao could not reject the null hypothesis at the $5 \%$ level of significance. With respect to Pedroni, among the four statistics that are based on within - dimension, Modified VR, Modified PP, rejected the null hypothesise at the $1 \%$ level of significance while the other two statistics failed to reject the null at the 5\% level of significance. According to the Monte Carlo simulation of Pedroni, the panel ADF and PP are the most appropriate tests statistics for this analysis, since they are working more appropriately in the case of the middle sample size in addition that the four statistics assume that the regressors are endogenous and can be serially correlated as well. Lastly, the same-AR test statistic, VR, of Westerlund (2005) failed to reject the null hypothesis at the 5\% level of significance.

As seen in Table 19 and based on the panel statistics taking into consideration that the basic dependent variable is the HDI; the panel can be regarded as being non-cointegrated.

Table 19. Results of Second generation Panel Co-integration Tests-High Income Countries Panel.

\begin{tabular}{llllll}
\hline Dependent Variable & Statistic & Value & Z-Value & P-Value \\
\hline \multirow{2}{*}{ HDI } & $\mathrm{P}_{\mathrm{t}}$ & -3.72 & 5.66 & 1.00 & Robust P-Value \\
& $\mathrm{P}_{\mathrm{a}}$ & -0.09 & 5.64 & 0.08 \\
\end{tabular}

Source: Author's own calculations. Note (1) number of replications are equal to 50 and only one lead is added to ensure that the variables are weakly exogenous and (2) Only one lag was selected due to the short time series and with the Bartlett kernel window width set to 4 (T/100)2/9 $\approx 3$.

Table 20 shows the results of the first-generation panel cointegration assuming specification with intercept only, the three statistics of Kao could not reject the null hypothesis at the $5 \%$ level of significance. With respect to Pedroni,, both of the Modified VR and Modified PP, rejected the null hypothesise at the $1 \%$ level of significance while the other two statistics failed to reject the null at the $5 \%$ level of significance. Lastly, the same-AR test statistic of Westerlund (2005), VR, failed to reject the null hypothesis at the $1 \%$ level of significance.

Table 20. First generation Panel Co-integration Tests-Upper Middle Income Countries.

\begin{tabular}{lllllllll}
\hline $\begin{array}{l}\text { Cointegration } \\
\text { Test-Intercept }\end{array}$ & \multirow{2}{*}{ Kao Test } & & & \multicolumn{2}{l}{ Pedroni Test } & Westerlund \\
\cline { 5 - 8 } & & & & H1: common AR coefficients (within-dimension) & Test \\
\hline Test Statistic & ADF & DF & Modified DF & Modified VR & Modified PP & Panel PP & Panel ADF & VR \\
HDI & -0.986 & -1.420 & 0.592 & $-4.964 * * *$ & $3.081^{* * *}$ & -0.855 & 0.569 & 1.933 \\
\hline
\end{tabular}

Source: Author's own calculations using Stata. Note (1) PP=Phillips-Perron; ADF=Augmented Dickey Fuller, VR=Variance Ratio. (2) Automatic lag selection is based on AIC criterion with a maximum of 3 lags and selected 2 lags for Kao and only one lag for Pedroni test, (3) the null hypothesis is no co-integration versus the alternative one that assumes the same AR parameter across all panels.

Table 21. Second generation Panel Co-integration Tests-Upper Middle Income Countries.

\begin{tabular}{llllll}
\hline Dependent Variable & Statistic & Value & Z-Value & P-Value \\
\hline \multirow{2}{*}{ HDI } & $\mathrm{P}_{\mathrm{t}}$ & -4.81 & 4.63 & 1.00 & Robust P-Value \\
& $\mathrm{P}_{\mathrm{a}}$ & -0.25 & 5.44 & 0.14 \\
\end{tabular}

Source: Author's own calculations. Note (1) number of replications are equal to 50 and only one lead is added to ensure that the variables are weakly exogenous and (2) Only one lag was selected, due to limited number of observations and with the Bartlett kernel window width set to 4 (T/100)2/9 $\approx 3$.

As shown in Table 21, Westerlund (2007) cointegration test was implemented and based on the panel statistics, both of them $\left(\mathrm{P}_{\mathrm{t}}\right.$ and $\mathrm{P}_{\mathrm{a}}$ failed to reject the null hypotheses after bootstrapping for all of the variables concluding that the panel is non-cointegrated. Taking into consideration that the basic dependent variable is the HDI, the panel can be regarded as being non-cointegrated.

Table 22 shows the results of the first-generation panel 
cointegration assuming specification with intercept only for Pedroni test. Kao test statistics show that the null hypothesis is rejected at the $1 \%$ level of significance confirming the presence of level relationship between the panel variables. However, at the $1 \%$ significance level as well, three statistics of Pedroni couldn't reject the null hypothesis besides that the modified VR statistic of Westerlund as well. Hence, according to the previous results, still no conclusive outcome can be clearly made regarding confirming or not the presence of cointegration.

Table 22. First generation Panel Co-integration Tests -Lower Middle Income Countries.

\begin{tabular}{|c|c|c|c|c|c|c|c|c|}
\hline \multirow{2}{*}{$\begin{array}{l}\text { Cointegration } \\
\text { Test-Intercept }\end{array}$} & \multirow{2}{*}{\multicolumn{2}{|c|}{ Kao Test }} & \multirow[b]{3}{*}{ Modified DF } & \multirow{2}{*}{\multicolumn{4}{|c|}{$\begin{array}{l}\text { Pedroni Test } \\
\text { H1: common }\end{array}$}} & \multirow{3}{*}{$\begin{array}{l}\text { Westerlund } \\
\text { Test } \\
\text { VR } \\
\end{array}$} \\
\hline & & & & & & & & \\
\hline Test Statistic & ADF & DF & & Modified VR & Modified PP & Panel PP & Panel ADF & \\
\hline HDI & $-3.36 * * *$ & $-3.87 * * *$ & $-4.28 * * *$ & $-6.37 * * *$ & 1.89 & -1.86 & -1.68 & 1.03 \\
\hline
\end{tabular}

Source: Author's own calculations. Note (1) PP=Phillips-Perron; ADF=Augmented Dickey Fuller, VR=Variance Ratio. (2) Automatic lag selection is based on AIC criterion with a maximum of 3 lags and selected 2 lags for Kao and only one lags for Pedroni test, (3) the null hypothesis is no co-integration versus the alternative one that assumes the same AR parameter across all panels.

Also for the panel of low income countries as seen in table 23 and after applying the Westerlund (2007) cointegration test, based on the panel statistics, both of the panel statistics failed to reject the null hypotheses after bootstrapping for all of the variables concluding that the panel is non-cointegrated. Taking into consideration that the basic dependent variable.

Table 23. Results of Second generation Panel Co-integration Tests -Lower Income Countries.

\begin{tabular}{lllll}
\hline Dependent Variable & Statistic & Value & Z-Value & P-Value \\
\hline \multirow{2}{*}{ HDI } & $\mathrm{P}_{\mathrm{t}}$ & -8.57 & 0.36 & 0.64 \\
& $\mathrm{P}_{\mathrm{a}}$ & -0.20 & 4.71 & 0.06 \\
\hline
\end{tabular}

Source: Author's own calculations. Note (1) number of replications are equal to 50 and only one lead is added to ensure that the variables are weakly exogenous and (2) Only one lag was selected, due to limited number of observations and with the Bartlett kernel window width set to 4 (T/100) $2 / 9 \approx 3$.

Table 24 shows the results of the first-generation panel cointegration assuming specification with intercept only for Pedroni test. Kao test statistics of the modified DF and DF cannot reject the null hypothesis at the $5 \%$ and $1 \%$ levels of significance while only the ADF statistic rejects the null confirming the presence of level relationship between the panel variables. Additionally, at the $1 \%$ and $5 \%$ significance levels as well, three statistics of Pedroni couldn't reject the null hypothesis which are the modified PP, panel PP and panel ADF beside that the modified VR statistic couldn't reject the null as well. Thus at the $1 \%$ significance level, the majority of the tests statistics couldn't reject the null and hence the panel can be considered as being non-cointegrated.

After applying the Westerlund (2007) cointegration test as shown in table 25 and based on the panel statistics, both of the panel statistics failed to reject the null hypotheses after bootstrapping for all of the variables concluding that the panel is non-cointegrated. Taking into consideration that the basic dependent variable is the HDI, the panel can be regarded as being non-cointegrated.

Table 24. First generation Panel Co-integration Tests -Low income countries.

\begin{tabular}{|c|c|c|c|c|c|c|c|c|}
\hline \multirow{2}{*}{$\begin{array}{l}\text { Cointegration } \\
\text { Test-Intercept }\end{array}$} & \multirow{2}{*}{\multicolumn{2}{|c|}{ Kao Test }} & \multicolumn{5}{|c|}{ Pedroni Test } & \multirow{2}{*}{ Westerlund Test } \\
\hline & & & & H1: common & coefficients (w & in-dimensi & & \\
\hline Test Statistic & ADF & DF & Modified DF & Modified VR & Modified PP & Panel PP & Panel ADF & VR \\
\hline HDI & $-3.66 * * *$ & -2.14 & -1.57 & $-5.17 * * *$ & 1.70 & 0.004 & -0.180 & 0.777 \\
\hline
\end{tabular}

Source: Author's own calculations using Stata. Note (1) PPP=Phillips-Perron; ADF=Augmented Dickey Fuller, VR=Variance Ratio. (2) Automatic lag selection is based on AIC criterion with a maximum of 3 lags and selected 2 lags for Kao and for Pedroni test, (3) the null hypothesis is no co-integration versus the alternative one that assumes the same AR parameter across all panels.

Table 25. Results of Second generation Panel Co-integration Tests - Low Income Countries.

\begin{tabular}{lllll}
\hline Dependent Variable & Statistic & Value & Z-Value & P-Value \\
\hline \multirow{2}{*}{ HDI } & $\mathrm{P}_{\mathrm{t}}$ & -0.684 & 5.403 & 1.00 \\
& $\mathrm{P}_{\mathrm{a}}$ & -0.152 & 3.837 & 0.700 \\
\end{tabular}

Source: Author's own calculations. Note (1) number of replications are equal to 50 and only one lead is added to ensure that the variables are weakly exogenous, (2) Only one lag was selected due to limited number of observations, with the Bartlett kernel window width set to 4 (T/100)2/9 $\approx 3$.

\subsection{Panel VAR}

\section{(i). High Income Countries Panel}

The first step in estimating PVAR is the selection of the lag length where the panel VAR analysis is only being estimated after choosing the optimal lag order in the panel VAR specification. According to the AIC criteria, the appropriate lag is here 1 period as in shown in Table 26. 
Table 26. PVAR Lag Order Selection Criterion-High Income Countries Panel.

\begin{tabular}{llll}
\hline Lags & BIC & AIC & QIC \\
\hline 1 & -517.785 & $-35.946^{*}$ & -222.971 \\
2 & -334.631 & -13.405 & -138.088 \\
3 & -157.249 & 3.3629 & -58.97875 \\
\hline
\end{tabular}

Source: Author's own calculations. Note (1) * indicates lag order selected by the AIC criterion.

After choosing the number of lags and found to be equal to only one lag, it should be noted again that the SYS-GMM by default produces just identified system of equations as it employs number of instruments equal to number of regressors in each equation and hence the default is to use only one lag as an instrument. However, by construction, first differencing introduces serial correlation in the model and hence the remedy to such a problem is applied only through adding more lags to the system as instruments. After the addition of more lags to the system, Hansen's $\mathrm{j}$ test should be applied to test the validity of the over identifying instruments. Thus, a Prerequisite step for estimating the PVAR is to investigate for the presence or absence of serial correlation as presented in table 27.

As shown in table 27 and after applying the Wooldridge (2002) [46] test, serial correlation was detected at the 5\% level of significance and hence more lags should be added as instruments while the validity of these instruments should be checked through Hansen's over identification test. The next step is to apply the panel VAR.

Table 27. Wooldridge Test for Autocorrelation in Panel Data-High Income Countries Panel.

\begin{tabular}{ll}
\hline Dep. Variable & F-Statistic \\
\hline HDI & $527.314^{* *}$ \\
\hline
\end{tabular}

Source: Author's own calculations. Notes: (1) The null hypothesis is no first order autocorrelation and (2) The p-value are in parenthesis.

As presented in table 28, regarding the effect of financial development on the HDI of these countries, it can be seen that the financial development positively influence the HDI but at low significance rate at the $10 \%$ level. This is because it is acceptable to claim that as the high income countries strolled into that steady state of growth, it is extremely difficult to raise growth rates just by investing capital and increase the amount of loans granted. Then, it can be securely said that countries of the developed world has undergone into what economist outlines as "long run convergence" or "consistent nation". At this stage of development, countries have passed excessive speed of economic growth and stepped right into a near stagnation nation with near-0 GDP growth.

In analyzing the relationship between per capita $\mathrm{CO}_{2}$ emissions and HDI, it can be perceived that HDI is negatively affecting the per capita $\mathrm{CO}_{2}$ emissions where for every 1-unit increase in HDI, the emissions level fall by $4.3 \%$ and is significant at the $5 \%$ significance level. This means that as these countries attain better development levels, the level of emissions decrease where such a result should refer to the idea that better development levels and quality of life result in better environmental quality. In addition to, such an outcome refers to the increased awareness of these high income countries to the issues of environmental damage and quality of life. On the contrary, as these emissions increase by $1 \%$, HDI increases but by almost insignificant amount that makes such a rise in the HDI almost invisible specifically that such an outcome is statistically weakly significant at the $10 \%$ level. Soukiazis et al., (2017) [37], for the OECD countries, found that the $\mathrm{CO}_{2}$ emissions per capita associated mostly with the consumption of fossil energy sources affects negatively the human development levels as expected, but without having any statistical relevance.

The negative effect of HDI on the per capita $\mathrm{CO}_{2}$ emissions can also be illustrated in the light of the negative effect of the energy intensity on the level of emission as well. As presented in table 28 , as energy intensity increases by $1 \%$, the level of emissions decrease by $0.26 \%$. Such an outcome can be justified from the point of view that as these countries achieve higher levels of energy intensity, their level of $\mathrm{CO}_{2}$ emissions are reduced and as such reflect the increasing awareness of the high income countries to the important role of improving their energy intensity to achieve the desired effect from lessening the $\mathrm{CO}_{2}$ emissions. This finding is similar to existing energy literature such as Hatzigeorgiou et al., (2011) [15] for the case of Greece as one of the high income countries in the panel.

Table 28. Panel VAR model.

\begin{tabular}{lllllll}
\hline \multirow{2}{*}{ Dependent variables } & \multicolumn{2}{l}{ (GMM Estimates) Independent Variables } & & \\
& D. HDI (-1) & D. LPCO2 (-1) & D. LEI (-1) & D. LREC (-1) & D. LFD (-1) & D. LTO (-1) \\
\hline D. HDI & $.15379^{* *}$ & $.00400^{*}$ & -.00277 & -0.000 & $.00270^{*}$ & -.00066 \\
D. LPCO2 & $-4.334^{* *}$ & -.0563 & $-.26376^{* * *}$ & .00483 & .01249 & .01249 \\
D. LEI & -.41594 & -.02647 & -.1011 & .00987 & -.0058 & -.03060 \\
D. LREC & -4.8109 & .03301 & .01012 & -.01737 & -.0048 & -.14327 \\
D. LFD & 1.1335 & .00346 & $-.1809^{* *}$ & -.00119 & $.10135^{*}$ & -.04013 \\
D. LTO & $1.5539^{* * *}$ & $-.11186^{* * *}$ & $.15650^{* * *}$ & .00892 & .01829 & .19843 \\
\hline
\end{tabular}

Source: Authors' calculations. Note: (1) The panel VAR model is estimated by system GMM, (2) cross sectional means have been removed as being subtracted from each variable in the model before estimation. (3) stability condition is satisfied where all of the eigenvalues lie inside the unit circle, (4)******* indicates significance at the $10 \%, 5 \%$ and $1 \%$ levels of significance, $(5)$ number of panels=32 and years=22 after taking one lag and two instruments giving a total number of observations equal to 704 and (6) Hansen's $\mathrm{J} \mathrm{chi}^{2}=30.8952(\mathrm{p}=0.710)$. 
Nevertheless, defending the insignificant effect of renewable energy consumption on $\mathrm{CO}_{2}$ emissions in these countries, it is possible to say that these countries may not have reached still the threshold point at which renewable energy starts to lessen significantly and apparently the $\mathrm{CO}_{2}$ emissions. According to Chiu and Chang (2009) [6], renewable energy supply should constitute for about $8.39 \%$ of total energy supply to have any impact on mitigating $\mathrm{CO} 2$ emissions. Hence and according to the World Bank Development indicators 2015 the renewable energy consumption as a percent of the total final energy consumption for some selected countries respectively are; Bahamas $1.21 \%$, Saudi Arabia 0.01\%, Israel 3.71, Japan 6.30\%, Malta 5.36\%, UK $8.71 \%$, USA $8.72 \%$, United Arab of Emirates $0.14 \%$ and finally Belgium a little bit further with $9.20 \%$. However, a study by Bilan et al., (2019) [2], concluded that renewable energy consumption significantly and negatively decreases $\mathrm{CO}_{2}$ emissions for the EU countries during the period 1990-2015. They concluded that these countries should boost their supporting policies to promote the quicker development of the renewable energy sector.

Besides, concerning the influence of energy intensity on financial development, there are not many studies in the literature to investigate such influence where the empirical studies that investigate this nexus remain sparse. As presented, a $1 \%$ increase in the energy intensity reduces financial development in these countries by $0.10 \%$ with low significance at the $10 \%$ level. Consequently, the lower the energy efficiency in these countries, the greater will be the credit constraints and the lower will be the development of the financial sector. This could be explained as that investments in energy efficiency remain to be discouraging for more financial help in this area.

With respect to the effect of HDI on trade openness it can be seen that for every one-unit increase in the HDI, the trade openness increase by $1.5 \%$. This means that higher levels of human development stimulates more trade activities with the external world and that as standards of living increase, countries can have a chance to consume different kinds of goods and services that cannot be domestically acquired or produced relatively cheaply. Finally, at the $1 \%$ level of significance, for every $1 \%$ increase in the energy intensity, trade openness increase by $0.15 \%$. This means that the governments of these countries should establish energy consumption policies taking into consideration how it affect trade because the shortage of energy supply will highly affect the imports and exports of these countries. It should also be noted that higher energy intensity means that these countries are utilizing high levels of energy for trade issues and hence energy conservation policies will ultimately reduce trade. Thus, these countries need to advance their technology requirements in order to use energy efficiently without negatively affecting trade activities.

(ii). Upper Middle Income Countries

These countries are enjoying good incomes and having per capita output ranging from a minimum of $\$ 729.1606$ to a maximum of $\$ 14920$ per year. They represent countries with high levels of human development, according to the Unites Nations Development Program, ranging from a minimum of 0.477 for Guatemala in 1990 to 0.828 for Argentina in 2015 (WDI 2019). The mean share of renewable energy in the total final energy consumption represents $26.40 \%$ higher than that of the high income countries. Among the top three nations for renewables consumption in the world, China is an indisputable renewable growth leader, accounting for over $40 \%$ of the total global clean energy mix by 2022 .

As previously mentioned, selection of the lag length is important in any panel VAR model and according to the AIC criteria, the appropriate lag is here 1 period as in shown in table 29. Then, following the same steps as done before, serial correlation should be tested and if found can be treated by adding more lags as instruments. Thus, table 30 represents the Wooldridge (2002) test for autocorrelation in Panel Data.

Table 29. PVAR Lag Order Selection Criterion.

\begin{tabular}{llll}
\hline Lags & BIC & AIC & QIC \\
\hline 1 & -575.281 & $-96.8720^{*}$ & -282.833 \\
2 & -384.917 & -65.9777 & -189.951 \\
3 & -201.203 & -41.7336 & -103.720 \\
\hline
\end{tabular}

Source: Author's own calculations. Notes $(1) *$ indicates lag order selected.

Table 30. Wooldridge Test for Autocorrelation in Panel Data.

\begin{tabular}{ll}
\hline Dependent Variable & F-Statistic \\
\hline HDI & $134.648 * *$ \\
\hline
\end{tabular}

Source: Author's own calculations. Notes: (1) The null hypothesis is no first order autocorrelation and (2) $*, * *, * * *$ indicates significance at the $10 \%, 5 \%$ and $1 \%$ levels of significance

Thus and according to the results in table 30 , it can be confirmed that serial correlation does exist at the $5 \%$ level of significance, which should lead to the addition of further lags as instruments. By testing for the validity of the instruments, the null hypothesis of Hansen-J test, was not rejected at the 1\% level of significance referring to the validity of selecting three lags as valid instruments. After the validity of the instruments have been confirmed, the panel VAR should estimates are to be presented as shown in table 31 .

According to table 31, lagged value of HDI positively affect the current ones so that for every 1-unit increase in the HDI of this year, the HDI of the next year would be raise by 0.23 units. This means that more development brings on more progress and success leading to increasing the index of human development of these countries. Nevertheless, trade openness and human development index positively and significantly influence each other at the $1 \%$ and $10 \%$ levels of significance. It is considered that openness to trade enables more economic performance through increasing competition and allowing domestic firms to have to have better foreign technology, which is supportive to raising the domestic productivity and allowing residents to have the luxury of more products that raise standards of living and hence human development. Also, as mentioned by Grossman and Helpman $(1989,1991)$ [11, 
12], that if trade openness enables the countries to specialize in the products of their comparative advantage, then this would enables the achievement of better and higher human development.

When the dependent variable is the renewable energy consumption, it can be seen higher indexes for the human development motivate more renewable energy consumption as a share of total energy consumption. Such a conclusion means that these countries are encouraging the increasing share of renewable in their energy supply mix and giving the clean sources of energy a great importance. For instance, with regard to the newly industrialized countries (NIC's), these countries are approaching renewables as part of the industrialization process given that they are considered as inputs in the manufacturing process. Considering this, it can be seen that China for instance has grown in the past decade to become a renewables superpower, dominating all industrialized countries in its levels of renewables. This means that in order to be able to raise standards of living, afford access to modern energy services, utilize energy more efficiently, protect the global environment and guarantee reliable energy supplies, green growth must play a key role. In addition to and as previously mentioned that higher rate of energy intensity indicates lower rates of energy efficiency and hence these countries should do more effort in investigating how to lessen the energy intensity rates for the sake of other influencers that boost their HDI.
Moreover, trade openness and financial development are seen to both negatively influence renewable energy consumption at the $1 \%$ and $10 \%$ levels of significance in this panel. These results raise concerns regarding the ineffectiveness of the trade liberalization policies in motivating more renewable energy consumption and thus marginalizing the prospects of renewables consumption within these economies. However, such a conclusion is not as the results concluded by Murshed, M., (2018) [2] who confirmed a positive effect of trade openness on renewable energy consumption, for a panel including Srilanka for instance, during the period of (2000-2017). With respect to the influence of financial development, it is perceivable that the transition to more renewable and sustainable energy sources requires huge investments. In fact, the role of renewables in developing countries like China, Brazil and India, is rapidly growing and attract the majority of investments in these countries. However, renewable energy technologies should first prove themselves commercially before they can make a difference (Scholtens, B. et al., 2015) [34]. One possible explanation for the negative effect of financial development on renewables, is that in the short run, might be due to the technological effect, the limited annual operating hours and uncertainty about the costs appear to limit the role of domestic credit to the renewable sources. In fact, renewable energy technologies are recognized for their high upfront costs and as such being largely dependent on external finance.

Table 31. Panel VAR model.

\begin{tabular}{|c|c|c|c|c|c|c|}
\hline \multirow{2}{*}{ Dependent variables } & \multicolumn{6}{|c|}{ (GMM Estimates) Independent Variables } \\
\hline & D. HDI (-1) & D. LREC (-1) & D. LPCO2 (-1) & D. LEI (-1) & D. LFD (-1) & D. LTO (-1) \\
\hline D. HDI & $.2303 * * *$ & -.00215 & -.00218 & .00106 & -.00056 & $.00476 * * *$ \\
\hline D. LREC & $5.6020 * *$ & $-.12488^{*}$ & $-.31868 * * *$ & $.49895 * * *$ & $-.0946 * * *$ & $-.13403 *$ \\
\hline D. $\mathrm{LPCO} 2$ & $2.7115^{* * *}$ & -.01467 & $-.22832 * * *$ & -.00899 & .02601 & .05663 \\
\hline D. LEI & $-2.8047 * *$ & -.00917 & -.01165 & -.07213 & $.07158 * * *$ & $-.05785 * *$ \\
\hline D. LFD & $16.5129 * * *$ & -.00093 & -.16290 & .18413 & $.10435 *$ & -.03680 \\
\hline D. LTO & $2.2000^{*}$ & .0496 & .09914 & .07239 & .00660 & .02796 \\
\hline
\end{tabular}

Source: Authors' calculations. Note: (1) The panel VAR model is estimated by system GMM, (2) cross sectional means have been removed as being subtracted from each variable in the model before estimation. (3) stability condition is satisfied where all of the eigenvalues lie inside the unit circle, (4) $* * * * * *$ indicates significance at the $10 \%, 5 \%$ and $1 \%$ levels of significance, $(5)$ number of panels $=31$ and years $=21$ after taking one lag and three instruments giving a total number of observations equal to 651 and (6) Hansen's $\mathrm{J} \mathrm{chi}^{2}=102.60258(\mathrm{p}=0.011)$.

Furthermore, when the per capita $\mathrm{CO} 2$ emissions is the dependent variable, results show that the consumption of renewable energy although being negative but insignificant. These countries failed to have a beneficial effect on environmental quality, though they enjoy on the average a reasonable consumption of renewables in their energy supply mix making around $26.3 \%$ on the average of the total energy consumption. These results are similar to Apergis et al. (2010) [1] who found, for a group of 19 developed and developing countries, that renewable energy consumption does not contribute to reductions in $\mathrm{CO}_{2}$ emissions in the short run. This might be because that more time and capacity is needed in order for these sources to significantly contribute to the decarbonization of the power sector and reduce environmental degradation. Additionally, the HDI is observed to positively influence the per capita $\mathrm{CO}_{2}$ emissions at the $1 \%$ level of significance. This means that higher development is being inefficiently achieved represented at the expense of the environmental quality. Hence, although more development in these countries are motivating and encouraging the increasing use of renewables but still is being achieved at higher levels of $\mathrm{CO}_{2}$ emissions. This is because upper middle-income countries are currently experiencing great structural changes towards more industrialized economies. Sohag, K., et al. (2017) [36] concluded that industrial and service sectors motivated more $\mathrm{CO}_{2}$ emissions in middle-income economies during the period of (1980-2012).

With respect to the energy intensity as a dependent variable, the results reveal a negative relationship between it and the HDI. That is, as the countries achieve a higher level of human development, energy intensity would go down and hence energy efficiency is improved. This means that as the HDI of these countries happened to cause the $\mathrm{CO}_{2}$ emissions positively but at the same time, it stimulates utilization of 
renewable energy consumption, which might be the reason for better energy efficiency issues accompanied with better HDI. With respect to the energy intensity as a dependent variable, the results reveal a negative relationship between it and the HDI. That is, as the countries achieve a higher level of human development, energy intensity would go down and hence energy efficiency is improved. This means that as the HDI of these countries happened to cause the $\mathrm{CO}_{2}$ emissions positively but at the same time, it stimulates utilization of renewable energy consumption, which might be the reason for better energy efficiency issues accompanied with better HDI.

Last of all, HDI is positively affecting financial development and is highly significant at the $1 \%$ level. Human development for any country implicitly requires some technical progress, which requires savings and investments where the financial system facilitates it. Thus, it is perceived that as a country experiences better standards of living, the role-played by the financial system as the mobilisers of savings and the source of investment increase as well. In fact, the deepening of the financial system seems to be a result rather than a cause of development in these economies.

(iii). Lower Middle Income Countries

These countries are encountering relatively low incomes and having per capita real GDP ranging from a minimum of $\$ 411$ to a maximum of $\$ 4308$ per year. They represent countries with relatively medium levels of human development, according to the United Nations Development Program, ranging from a minimum of 0.33 for Sudan in 1990 to 0.74 for Ukraine in 2014. The mean share of renewable energy in the total final energy consumption represents $46 \%$ considerably higher than that both of the higher income countries and upper middle income countries. For instance, in Zimbabwe, fuel wood is considered to be an important source of domestic energy for up to 90 per cent of people in the countryside (Wedocs, 2015) [42].

As previously mentioned, selection of the lag length is important in any panel VAR and according to the AIC criteria, the appropriate lag is here 1 period as in shown in table 32 . Following the same steps as done before, serial correlation should be tested and if found could be treated by adding more lags as instruments. Thus, table 33 represents the Wooldridge Test for autocorrelation in Panel Data. Thus and according to the results in table 33 , it can be confirmed that serial correlation does exist at the $5 \%$ level of significance. This should lead to the addition of further lags as instruments, yet Hansen J-test did not confirm the validity of using more instruments until four. Only at five instruments, the instruments were valid, yet using 5 instruments means that degrees of freedom are reduced and hence decreasing the precision of the regression estimates. In such a case, it is suggested that if $T$ is not too large then, it is more preferable to use clustering which allows for any kind of serial correlation. This is because; any other fix will likely has worse finite sample properties.

Table 32. PVAR Lag Order Selection Criterion.

\begin{tabular}{llll}
\hline Lags & BIC & AIC & QIC \\
\hline 1 & 334.8405 & $-33.8793^{*}$ & -152.1495 \\
2 & -166.059 & -15.57844 & -74.71355 \\
3 & - & - & - \\
\hline
\end{tabular}

Source: Author's own calculations. Notes: $(1) *$ indicates lag order selected by the AIC criterion.

Table 33. Wooldridge Test for Autocorrelation in Panel Data.

\begin{tabular}{ll}
\hline Dependent Variable & F-Statistic \\
\hline HDI & $869.276^{* *}$ \\
\hline
\end{tabular}

Source: Author's own calculations. Notes: (1) The null hypothesis is no first order autocorrelation and (2) $* * *, * * *$ indicates significance at the $10 \%, 5 \%$ and $1 \%$ levels of significance.

Accordingly and as observed in table 34, when the dependent variable is the HDI, it can be noticed that the lagged coefficient of the HDI is positively significant for the current value of the HDI. This means that more development in one-year raises the index for human development later for in the next year and this is reasonable well. Additionally, it can be noticed that the influence of renewable energy consumption on HDI is weakly significant and negative at the $10 \%$ level. According to Heal (2009) [16], the generation of electricity from renewable sources represents a costly process that takes a longer time to see the positive effects of such technological progress and investment in a renewable energy station.

Table 34. Panel VAR model.

\begin{tabular}{|c|c|c|c|c|c|c|}
\hline \multirow{2}{*}{ Dependent variables } & \multicolumn{6}{|c|}{ (GMM Estimates) Independent Variables } \\
\hline & D. HDI (-1) & D. LREC (-1) & D. LPCO2 (-1) & D. LEI (-1) & D. LFD (-1) & D. LTO (-1) \\
\hline D. HDI & $.4831 * * *$ & $-.00413 *$ & .00059 & -.00535 & .00055 & .00072 \\
\hline D. LREC & -.42120 & .05292 & .01886 & -.01400 & $-.0351 * *$ & .00538 \\
\hline D. LPCO2 & 2.2851 & -.1132 & $-.11272 * *$ & -.0456 & .0397588 & -.04671 \\
\hline D. LEI & -2.1463 & .05830 & $-.04980 * *$ & .05415 & -.0109 & -.03939 \\
\hline D. LFD & $8.395 * * *$ & .15516 & .07763 & -.32667 & .00836 & -.06040 \\
\hline D. LTO & -.71682 & $.10014^{* *}$ & .05078 & $-.1541 * *$ & .03320 & $-.19478^{*}$ \\
\hline
\end{tabular}

Source: Authors' calculations. (1) The panel VAR model is estimated by system GMM, (2) cross sectional means have been removed as being subtracted from each variable in the model before estimation. (3) Stability condition is satisfied where all of the eigenvalues lie inside the unit circle, (4) $*, * *, * * *$ indicates significance at the $10 \%, 5 \%$ and $1 \%$ levels of significance and (5) number of panels $=23$ and years $=23$ after taking one lag and one instrument.

It should be noted also that insignificance impact of the renewables on contributing to less $\mathrm{CO}_{2}$ emissions might due to the fact that the renewable energy consumed by these countries are mostly sourced from traditional biomasses, as previously stated, instead of clean modern renewable energy sources. For example, according to the IEA (2019) [19], 
traditional uses of biomass account for about half of renewable energy consumption in a number of top 20 energy-consuming countries like India and Indonesia in this panel. Similarly, Hasnisah, et al. (2019) [14] found that the renewable energy consumption effect is insignificant in contributing to less pollution regarding the $\mathrm{CO}_{2}$ emissions in a panel of developing counties in Asia including India, Indonesia, Bangladesh and Philippines. They suggested that consumption of energy from renewable sources was insufficient in reducing the impact of climate. In addition, as presented in table 34, lagged coefficient of $\mathrm{CO}_{2}$ emissions negatively and significantly affect its current value. This indicates that as the current $\mathrm{CO}_{2}$ emissions increase by $1 \%$, the $\mathrm{CO}_{2}$ emissions next year would go down by $0.11 \%$.

In addition to and as can be seen from table 34, more $\mathrm{CO}_{2}$ emissions in these countries help in reducing the energy intensity where for every $1 \%$ increase in the former, the latter is reduced by $0.049 \%$ and is significant at the $5 \%$ level. Thus, as environmental pollution increases, steps that are more empirical are being taken to reduce energy consumed per unit of output. According to Deichmann, U., et al. (2018) [7], they suggested that that when countries move beyond lower-middle-income levels, energy efficiency policies become far more critical for sustaining the rate of improvement in energy efficiency.

Furthermore, financial development negatively affect the renewable energy consumption where for every $1 \%$ increase in the former, the latter decreases by $0.035 \%$ and significant at the $5 \%$ level. This means that financial plans in these countries do not support energy transition and shift to renewable sources, which is the same conclusion as that achieved for the upper middle-income countries. Hence, it can be said that the domestic credit policies in these economies cannot effectively help moving on with their environmental sustainability policies or trying to help them in enabling the more utilization of clean sources of energy, that need extra domestic internal finance as well as external ones.

At last, and as found in the upper middle income countries, a 1 unit increase in the HDI leads to boosting more credit in the market by about $8.3 \%$ and is significant at the $1 \%$ level. These results are in line with Filippidis, I. and Katrakilidis, C., (2015) [10] who found that the human development effect on financial market, during the period from 1985 to 2008 , was positive and significant for the lower middle-income countries referring to its importance in the sustainable development process. Also, energy intensity negatively and significantly affecting trade openness at the 5\% level of significance which could mean that as more energy being consumed to produce a unit of output, the less will be the level of imports and exports in these countries. This might be explained that as more energy is being utilized to produce a unit of output, then less energy will be available to help in importing and or exporting goods.

(iv) Low Income Countries

These countries are suffering from very low incomes and having per capita real GDP ranging from a minimum of $\$ 200$ to a maximum of $\$ 3009$ per year. They represent countries with low levels of human development, according to the Unites Nations Development Program, ranging from a minimum of 0.18 for Rwanda in 1995 to a maximum of 0.59 for Congo in 2014. Additionally, these countries enjoys on the average a mean share of renewable energy of $82.40 \%$ considerably higher than that of all of the pervious panels. The share of renewable energy consumption for most of the countries are reasonable high reaching sometimes to $97.2 \%$ as in Burundi in 2005.

In conclusion, renewables almost entirely dominate the energy mix in these countries, with a $90.4 \%$ share in the total final energy consumption although it decreased a little from 94.5 to $93.5 \%$ between 2010 and 2012 . As the case in most of the African countries, traditional solid biofuels constitute the biggest share of renewable sources at $89.1 \%$ of the total final energy consumption in 2012. The modern solid biofuels contributed just 1.3\% (World Bank 2015) [48].

As previously mentioned, selection of the lag length is important in any panel VAR model and according to the AIC criteria, the appropriate lag is here 1 period as in shown in table 35. Following the same steps as done before, serial correlation should be tested and if found could be treated by adding more lags as instruments. Thus, table 36 presents the Wooldridge Test for autocorrelation in Panel Data.

Thus and according to the results in table 36 , it can be confirmed that serial correlation does exist at the $5 \%$ level of significance. This should lead to the addition of further lags as instruments and accordingly Hansen J-test that examines the validity of over identifying instruments should be implemented. At the beginning and before starting the analysis, it should be noted that the 15 low-income countries chosen for such analysis have been selected out of other low-income countries according to data availability. Out of these countries, it can be seen the twelve of them, which are Benin, Burundi, Central African Republic, Congo, Gambia, Guinea, Rwanda, Malawi, Sierra Leone, Tanzania, Togo and Uganda, represents the Sub Saharan African Countries (SSA). For this reason, it can be observed in the following analysis that the focus is on the SSA circumstances being the majority in this panel besides that the other countries share the same properties.

Table 35. PVAR Lag Order Selection Criterion.

\begin{tabular}{llll}
\hline Lags & BIC & AIC & QIC \\
\hline 1 & -338.715 & $-68.5299^{*}$ & -176.479 \\
2 & 184.576 & -49.4835 & -103.458 \\
3 & - & - & - \\
\hline
\end{tabular}

Source: Author's own calculations. Notes : $(1) *$ indicates lag order selected by the MAIC criterion.

Table 36. Wooldridge Test for Autocorrelation in Panel Data.

\begin{tabular}{ll}
\hline Dependent Variable & F-Statistic \\
\hline HDI & $293.462 * *$ \\
\hline
\end{tabular}

Source: Author's own calculations. Notes: (1) The null hypothesis is no first order autocorrelation and (2) $*, * *, * * *$ indicates significance at the $10 \%, 5 \%$ and $1 \%$ levels of significance. 
As presented in table 37, the energy intensity can be found to positively affect the HDI and significant at the 5\% level of significance. Such a positive relationship between the variables indicates that for these countries to develop more, they utilize higher levels of energy consumption per unit of gross domestic product. The statistical significance presented above demonstrate clearly that energy has an important influence on the HDI, particularly in the early stages of development as the case in this panel. This result can be acceptable to some extent as these countries, as referred to before, are still at their early stage of development and do not have access to the commercial energy but rather depends for survival on non-commercial energy sources, like firewood, and agricultural wastes, which they gather at a negligible monetary cost. Additionally, among the variables that raises the HDI is that trade openness though by a very small amount of $0.005 \%$ for every one-unit increase in the HDI. This is because, trade openness in general can positively influence the human development through open market strategies aiming at raising the countries welfare by specializing on the sectors of their comparative advantage, as David Ricardo discussed in the literature. Similar results have been obtained by Kabadayi, B., (2013) [18], who found that trade openness positively drives HDI for a panel of developing countries through the period between 1995 tom 2010 .
Nevertheless, at the 10\% level of significance, a 1-unit increase in these countries development levels raises their consumption of renewables by $0.8 \%$. This result demonstrates the important role of renewable energy consumption in their development and that as these countries are more developed, they prompt the increasing use of renewables, which should be directed toward cleaner sources of renewable energy rather than traditional solid biomasses. It should be noted as well that the low access of these countries to energy consumption justify the very low rates of carbon emissions they do have. Moreover, as more human development induces and drives the more consumption of renewable energy, it at the same time impedes the energy intensity, where a 1-unit increase in the HDI would reduce the energy intensity by $2.31 \%$ and is significant at the $5 \%$ level, as presented in table 37 . This outcome is a good one, which shows that these countries are getting to be more developed in the right path and direction where as they get more developed, not only they increase the use of renewables but at the same time induces more energy efficiency. Accordingly, the relationship between energy intensity and HDI is in line with the recommendations of UN sustainable energy, which advocated that the right path to development effectively come with a right path to use some minimum level of energy (Steinberger, 2016) [38].

Table 37. Panel VAR model.

\begin{tabular}{|c|c|c|c|c|c|c|}
\hline \multirow{2}{*}{ Dependent variables } & \multicolumn{6}{|c|}{ (GMM Estimates) Independent Variables } \\
\hline & D. HDI (-1) & D. LREC (-1) & D. LPCO2 (-1) & D. LEI (-1) & D. LFD (-1) & D. LTO (-1) \\
\hline D. HDI & $.5753 * * *$ & -.01234 & -.00368 & $.01146 * *$ & -.00017 & $.00582 * *$ \\
\hline D. LREC & $.84126 *$ & -.093408 & -.01914 & .03180 & .0068 & .00445 \\
\hline D. $\mathrm{LPCO} 2$ & 4.6634 & .28028 & -.12355 & -.01731 & .0146 & .00491 \\
\hline D. LEI & $-2.3124 * *$ & $.18992 *$ & .01795 & .04212 & -.01697 & -.01825 \\
\hline D. LFD & -3.7606 & -.05094 & -.12276 & $-.20985^{*}$ & $.12507 * *$ & -.0554 \\
\hline D. LTO & 3.5163 & .17697 & .07035 & $-.21902 *$ & -.01400 & $-.15564 * *$ \\
\hline
\end{tabular}

Source: Authors' calculations. Note: (1) The panel VAR model is estimated by system GMM. (2) Stability condition is satisfied where all of the Eigen values lie inside the unit circle. (3) $* * *, * * *$ indicates significance at the $10 \%, 5 \%$ and $1 \%$ levels of significance, (4) number of panels $=15$ and years $=22$ after taking one lag and two instruments and (5) Hansen's $\mathrm{J} \mathrm{chi}^{2}=51.312445(\mathrm{p}=0.047)$.

On the other hand side, renewable energy consumption is found to be positively influencing the energy intensity but is weakly significant at $10 \%$ level. Such a result can be attributed to the stage of development of these countries, whereas referred to before that these countries are at the early stages of development and as such tend to have higher rates of energy intensity. These results and observation is in line to what Scott, A., (2013) [35] found, where he illustrated that poorer countries tend to have greater energy intensity due to their industrial sector which are dominated by more energy intensive industries, e.g. materials processing rather than manufacturing, not up to date technology, and low-quality fuels that are used leading to poor energy efficiency. Therefore, while the region works to overcome a well-documented range of development challenges; widespread poverty, scattered conflicts, inadequate education, healthcare, and energy access, it must be integrated in the wider movement of developing globally in such a way that does not lead to increase the energy intensity.

Moreover, financial development and trade openness are found to be negatively influenced by the energy intensity. An explanation can be made in such a way that financial development tends to be affected by the degree of energy efficiency in the country so that the lower the amount of energy used to produce a unit of output, the more will be the financial development and the opposite is true. With respect to the relationship between energy intensity and trade openness, it is understandable that without enough energy supply, trade openness will be adversely influenced. This is because energy is an important factor of production in trade expansion and adequate consumption of energy is important for expanding trade via expanding exports and imports. Accordingly, if more energy is being exploited to produce a unit of output, then this means that such extra energy is diverted away from being used as input in the trade openness process given the deficiency available in the energy supply of these countries. On the contrary to the above-mentioned results, Le, T. H., (2016) [21] investigated the relationships between energy use, economic output, financial development and trade, based on a panel data of 15 
sub-Saharan African (SSA) countries during the period from 1983 to 2010 and found that no relationship does exist between energy use and any of the other variables mentioned.

\section{Conclusions}

This paper investigates the renewable energy-human development nexus for a number of selected countries separated into four panels that present the whole globe, according to income levels over the period of (1990-2015) using annual data. This study is the first to shed the light on the macroeconomic impacts of the renewables deployment on the human development at the global level through four different income level groups while including other variables as $\mathrm{CO}_{2}$ emissions, energy intensity, financial development and trade openness.

Conclusions refer to, in all of the four panels, as the human development increase in the current year by one unit; it raises the HDI for the next year by different magnitudes with the greatest increase occurs for the lower middle and low income countries. By default, these two panels are still the most in need for more human development and as such can be more sensitive for any kind of development. On the other hand, one of the important findings is the insignificant impact of the renewable energy consumption on the HDI among the selected countries in all of the panels except the lower middle-income countries. This outcome could be justified on the basis that as they try to move on and catch the path of the upper middle-income countries, they try at the same time to shift their renewables form being combustible and wastes to clean sources of energy. This is the reason for the negative impact on the HDI, because these clean sources are usually expensive at their first stage of implementation.

Additionally, the impact of renewable energy consumption in reducing the per capita $\mathrm{CO}_{2}$ emissions is found to be insignificant for all of the four panels. This conclusion does make sense where according to the World Bank (2018), the global share of renewable energy in total final energy consumption has hardly increased by only $0.8 \%$ between 2010 and 2015 , and expanded only marginally by $0.15 \%$ since 2014 reaching $17.5 \%$ in 2015 . According to the energy progress report 2018, in 164 countries, an absolute increment in total final energy consumption throughout the period 2014-2015 makes it very hard to increase the renewable energy share in total final energy consumption. This clarifies the reason for why renewable energy has expanded just gradually, in spite of the noteworthy development of world's absolute consumption of renewable energy and this expansion still makes its influence on both HDI and Carbon emissions to be insignificant.

In addition to, the results demonstrate that the energy intensity variable has an insignificant influence on the HDI for the high and middle-income countries but positively and significantly affecting that of the low-income countries. This is because higher levels of energy for these countries are capable of improving their level of development. Besides, renewable energy consumption positively affect the energy intensity in only the low income countries where these countries by default have high rates of energy intensity as they use more energy per unit of output being at the early stages of industrialization. On the other hand, for the low income and upper middle-income countries, a negative relationship between the HDI and energy intensity as a dependent variable exists, whereas the country becomes more developed, its energy intensity would be lessened. Moreover, in the upper middle income countries, as energy intensity increases, their renewable energy share increase as well pinpointing to the fact that these countries try to raise their share of renewables aiming at raising its energy efficiency. In addition, in the high-income countries, results show that higher HDI results in lower $\mathrm{CO}_{2}$ emissions while it leads to more $\mathrm{CO}_{2}$ emissions in the upper middle income countries. It seems that the upper middle-income countries still need to do more efforts to catch up with the high-income countries stage of curbing emissions.

Finally, it is important to draw the attention for the fact that the HDI for any country is the comprehensive result of many components and energy consumption constitute an indirect factor of them. It is expected that the lower middle and low-income countries will follow the same path undergone by the upper middle and high-income countries in order to achieve higher levels of development. The results of this research support the idea that the industrialized economies improvements regarding the quality of life have so far been mainly dependent on the exploitation of non-renewable energy sources while taking into consideration the important role of hydropower during the early stages of industrialization, as well as for many developing countries today. Regardless of its significance for productive purposes, access to clean and reliable energy represents an important prerequisite for fundamental determinants of human development including health, education, gender equality and environmental safety (UNDP, 2007).

\section{References}

[1] Apergis, N., Payne, J. E., Menyah, K. and Wolde-Rufael, Y., 2010. On the causal dynamics between emissions, nuclear energy, renewable energy, and economic growth. Ecological Economics, 69 (11), pp. 2255-2260.

[2] Bilan, Y., Streimikiene, D., Vasylieva, T., Lyulyov, O., Pimonenko, T. and Pavlyk, A., 2019. Linking between renewable energy, $\mathrm{CO} 2$ emissions, and economic growth: Challenges for candidates and potential candidates for the EU membership. Sustainability, 11 (6), p. 1528.

[3] Blundell, R. and Bond, S., 1998. Initial conditions and moment restrictions in dynamic panel data models. Journal of econometrics, 87 (1), pp. 115-143.

[4] Breitung, J., 2000. The local power of some unit root tests for panel data, in Baltagi, B. (ed). Advances in Econometrics. Non-stationary panels, panel cointegration, and dynamic panels. 
[5] Breusch, T. S. and Pagan, A. R., 1980. The Lagrange multiplier test and its applications to model specification in econometrics. The review of economic studies, 47 (1), pp. 239-253.

[6] Chiu, C. L. and Chang, T. H., 2009. What proportion of renewable energy supplies is needed to initially mitigate $\mathrm{CO} 2$ emissions in OECD member countries? Renewable and Sustainable Energy Reviews, 13 (6-7), pp. 1669-1674.

[7] Deichmann, U., Reuter, A., Vollmer, S. and Zhang, F., 2018. Relationship between energy intensity and economic growth: new evidence from a multi-country multi-sector data set. The World Bank.

[8] Dias, R. A., Mattos, C. R. and Balestieri, J. A., 2006. The limits of human development and the use of energy and natural resources. Energy Policy, 34 (9), pp. 1026-1031.

[9] Dincer, I., 2000. Renewable energy and sustainable development: a crucial review. Renewable and sustainable energy reviews, 4 (2), pp. 157-175.

[10] Filippidis, I. and Katrakilidis, C., 2015. Finance, institutions and human development: Evidence from developing countries. Economic research-Ekonomska istraživanja, 28 (1), pp. 1018-1033.

[11] Grossman, G. M. and Helpman, E., 1989. Comparative advantage and long-run growth (No. w2809). National Bureau of Economic Research.

[12] Grossman, G. M. and Helpman, E., 1991. Innovation and growth in the global economy. MIT press.

[13] Harris, R. and Tzavalis, E., 1996. Inference for unit roots in dynamic panels (No. 9604).

[14] Hasnisah, A., Azlina, A. A., \& Che, C. M. I. (2019). The Impact of Renewable Energy Consumption on Carbon Dioxide Emissions: Empirical Evidence from Developing Countries in Asia. International Journal of Energy Economics and Policy, 9 (3), 135.

[15] Hatzigeorgiou, E., Polatidis, H. and Haralambopoulos, D., 2011. CO2 emissions, GDP and energy intensity: a multivariate cointegration and causality analysis for Greece, 1977-2007. Applied Energy, 88 (4), pp. 1377-1385.

[16] Heal, G., 2009. The economics of renewable energy (No. w15081). National Bureau of Economic Research.

[17] IEA, I., 2019. Global Renewable Energy Policies and Measures Database.

[18] Kabadayi, B., 2013. Human development and trade openness: A case study on developing countries. Advances in Management and Applied Economics, 3 (3), p. 193.

[19] Kao, C., 1999. Spurious regression and residual-based tests for cointegration in panel data. Journal of econometrics, 90 (1), pp. 1-44.

[20] Kazar, G. and Kazar, A., 2014. The renewable energy production-economic development nexus. International Journal of Energy Economics and Policy, 4 (2), pp. 312-319.

[21] Le, T. H., 2016. Dynamics between energy, output, openness and financial development in sub-Saharan African countries. Applied Economics, 48 (10), pp. 914-933.

[22] Levin, A., Lin, C. F. and Chu, C. S. J., 2002. Unit root tests in panel data: asymptotic and finite-sample properties. Journal of econometrics, 108 (1), pp. 1-24.

[23] Love, I. and Zicchino, L., 2006. Financial development and dynamic investment behavior: Evidence from panel VAR', The Quarterly Review of Economics and Finance, 26. pp. 190-210.

[24] Martinez, D. M. and Ebenhack, B. W., 2008. Understanding the role of energy consumption in human development through the use of saturation phenomena. Energy Policy, 36 (4), pp. 1430-1435.

[25] Mazur, A., 2011. Does increasing energy or electricity consumption improve quality of life in industrial nations? Energy Policy, 39 (5), pp. 2568-2572.

[26] Murshed, M., 2018. Does improvement in trade openness facilitate renewable energy transition? Evidence from selected South Asian economies. South Asia Economic Journal, 19 (2), pp. 151-170.

[27] Niu, S., Jia, Y., Wang, W., He, R., Hu, L. and Liu, Y., 2013. Electricity consumption and human development level: A comparative analysis based on panel data for 50 countries. International Journal of Electrical Power \& Energy Systems, 53, pp. 338-347.

[28] Pedroni, P., 1999. Critical values for cointegration tests in heterogeneous panels with multiple regressors. Oxford Bulletin of Economics and statistics, 61 (S1), pp. 653-670.

[29] Pedroni, P., 2004. Panel cointegration: asymptotic and finite sample properties of pooled time series tests with an application to the PPP hypothesis. Econometric theory, 20 (3), pp. 597-625.

[30] Pesaran H. M., 2007. A Simple Panel Unit Root Test In The Presence Of Cross Section Dependence. Journal of Applied Econometrics, Vol. 22, PP. 265-312.

[31] Pesaran, M. H., 2003. A Simple Panel Unit Root Test in the Presence of Cross Section Dependence. Cambridge Working Papers in Economics No. 0346, University of Cambridge.

[32] Pîrlogea, C., 2012. The human development relies on energy. Panel data evidence. Procedia economics and Finance, 3, pp. 496-501.

[33] Roodman, D., 2009. How to do xtabond 2: An introduction to difference and system GMM in Stata. The Stata Journal, Vol. 9, Number 1, pp. 86-136.

[34] Scholtens, B. and Veldhuis, R., 2015. How does the development of the financial industry advance renewable energy? A panel regression study of 198 countries over three decades.

[35] Scott, A., 2013. Energy and low-carbon competitiveness: the case of low-income countries. ODI Working Papers 367. London: Oversees Development Institute.

[36] Sohag, K., Al Mamun, M., Uddin, G. S. and Ahmed, A. M., 2017. Sectoral output, energy use, and $\mathrm{CO}_{2}$ emission in middle-income countries. Environmental Science and Pollution Research, 24 (10), pp. 9754-9764.

[37] Soukiazis, E., Proenca, S. and Cerqueira, P. A., 2019. The interconnections between renewable energy, economic development and environmental pollution: A simultaneous equation system approach. The Energy Journal, 40 (4). 
[38] Steinberger, J. K., 2016. Energizing Human Development, s. 1.: UNDP.

[39] Stock, J. H., 1987. Testing for Common Trends. Journal of the American Statistical Association, 83, pp. 1097-1107.

[40] U. S Energy Information Administration, 2019. Data. Retrieved

from $<$ https://www.eia.gov/international/data/world/electricity/elect ricity-generation?>.

[41] Wang, Z., Zhang, B. and Wang, B., 2018. Renewable energy consumption, economic growth and human development index in Pakistan: evidence form simultaneous equation model Journal of cleaner production, 184, pp. 1081-1090.

[42] Wedocs, 2015. Zimbabwe. Retrieved from $<$ https://wedocs.unep.org/bitstream/handle/20.500.11822/2058 9/Energy_profile_Zimbabwe.pdf?sequence $=1 \&$ isAllowed $=\mathrm{y}>$.

[43] Westerlund, J. and Edgerton, D. L., 2007. A panel bootstrap cointegration test. Economics letters, 97 (3), pp. 185-190.
[44] Westerlund, J., 2005. New simple tests for panel cointegration. Econometric Reviews, 24 (3), pp. 297-316.

[45] Westerlund, J., 2007. Testing for error correction in panel data. Oxford Bulletin of Economics and statistics, 69 (6), pp. 709-748.

[46] Wooldridge, J. M. 2002. Econometric Analysis of Cross Section and Panel Data. Cambridge, MA: MIT Press.

[47] World Bank Organization, 2019. World Development Indicators. Retrieved from https://databank.worldbank.org/reports.aspx? source=2\&countr $\mathrm{y}=\mathrm{UMC \#}$ selected Dimension_WDI_Series.

[48] World Bank, 2015. Sudan's Forests National Corporation Launches Climate Change and Deforestation Project with World Bank Group Support. Retrieved from< https://www.worldbank.org/en/news/press-release/2015/09/02/ sudan-forests-national-corporation-launches-climate-change-a nd-deforestation-project-with-world-bank-group-support> . 